\title{
Hydrodynamic and water quality 3D modelling of the Nam Theun 2 Reservoir (Lao PDR): predictions and results of scenarios related to reservoir management, hydrometeorology and nutrient input
}

\author{
Modélisation $3 D$ de l'hydrodynamique et de la qualité d'eau \\ du réservoir de Nam Theun 2 : prédictions et résultats \\ de scénarios liés à la gestion du réservoir, \\ à l'hydrométéorologie et à l'apport de nutriments
}

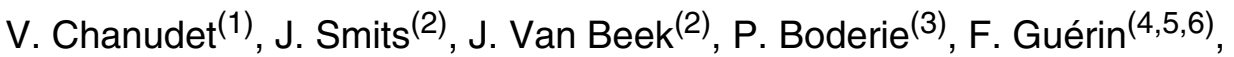 \\ D. Serça ${ }^{(7)}$, C. Deshmukh ${ }^{(7)}$, S. Descloux ${ }^{(1)}$ \\ (1) Électricité de France, Hydro Engineering Centre, Sustainable Development Dpt, Savoie Technolac, \\ 73373 Le Bourget du Lac, France \\ vincent.chanudet@edf.fr \\ (2) Deltares, Marine and Coastal Systems, PO Box 177, 2600 MH Delft, The Netherlands \\ (3) Deltares, Inland Water Systems, PO Box 177, 2600 MH Delft, The Netherlands \\ (4) Université de Toulouse, UPS (OMP), LMTG, 14 avenue Edouard Belin, 31400 Toulouse, France \\ (5) IRD, LMTG, 14 avenue Edouard Belin, 31400 Toulouse, France \\ (6) Departamento de Geoquimica, Universidade Federal Fluminense, Niteroi-RJ, Brasil \\ (7) Laboratoire d'Aérologie, Observatoire Midi-Pyrénées, 14 avenue Edouard Belin, 31400 Toulouse, France
}

\begin{abstract}
A 3D water quality model has been applied to predict medium term evolution of the water quality in the Nam Theun 2 Reservoir and also to quantify the effect of various scenarios. 15-year simulations show that the oxygen concentration will continue to increase in the water column although the hypolimnion will remain anoxic in some areas of the Reservoir. In parallel, the concentration of reduced compounds will decrease with time. The significance of the hydrodynamics in water quality evolution is pointed out with two scenarios in which natural or human forcings have been modified. The comparison of simulations made for years with contrasted hydrometeorological conditions shows that and duration of major hydrometeorological related events (rainfall, flood and air temperature drop) have a major influence on the seasonal evolution of water quality in the whole Reservoir. Simulations also show that the physico-chemical quality of the water released downstream of the power house would have been different if the commissioning had been carried out immediately after the impoundment. Finally, the model has been used to quantify the impact of an increase of the $\mathrm{NO}_{3}{ }^{-}$and $\mathrm{PO}_{4}{ }^{3-}$ incoming flux consecutive to potential changes in the watershed land use. The fluxes have been multiplied by a factor two separately ( 2 scenarios) and together. While the additional load of $\mathrm{NO}_{3}{ }^{-}$has almost no impact on physico-chemistry and phytoplankton activity, the
\end{abstract}


increase of $\mathrm{PO}_{4}{ }^{3-}$ leads to a larger increase of chlorophyll-a close to the Intake than close to the dam.

Key words - water quality modelling, Nam Theun 2 Reservoir, simulation, medium term evolution

Résumé - Un modèle numérique 3D a été utilisé pour prédire l'évolution à moyen terme de la qualité d'eau du réservoir de Nam Theun 2 et également pour quantifier l'effet de différents scénarios. Les simulations sur 15 ans montrent que la concentration en oxygène dans la colonne d'eau continuera à augmenter bien que l'hypolimnion restera anoxique dans certaines parties du réservoir. En parallèle, la concentration des composés réduits va diminuer avec le temps. L'importance de l'hydrodynamique dans l'évolution de la qualité d'eau est mise en avant dans deux scénarios dans lesquels les forçages naturel ou anthropique ont été modifiés. La comparaison de simulations réalisées pour des années présentant des conditions hydrométéorologiques contrastées a permis de mettre en évidence que la date et la durée des événements hydrométéorologiques majeurs (précipitations, crue, chute de température) ont une influence importante sur l'évolution saisonnière de la qualité d'eau dans l'ensemble du réservoir. Les simulations montrent également que la qualité physico-chimique de l'eau restituée à l'aval de l'usine aurait été différente si la mise en service avait eu lieu immédiatement après la mise en eau. Enfin, le modèle a été utilisé pour quantifier l'impact de l'augmentation des flux entrants de $\mathrm{NO}_{3}{ }^{-}$et $\mathrm{PO}_{4}{ }^{3-}$ suite à d'éventuelles modifications des usages sur le bassin versant. Alors que l'augmentation de la charge en $\mathrm{NO}_{3}{ }^{-}$n'a pratiquement aucun impact sur la physico-chimie et sur l'activité phytoplanctonique, l'augmentation du flux de $\mathrm{PO}_{4}{ }^{3-}$ induit une augmentation de la chlorophylle $a$, hausse plus marquée à proximité de la prise d'eau que près du barrage.

Mots clés - modélisation de la qualité d'eau, réservoir de Nam Theun 2, simulation, évolution à moyen termes

\section{INTRODUCTION}

Water quality in reservoirs depends on many parameters and processes, including hydrodynamics. Interactions are so numerous (Stumm \& Morgan, 1996) that it is difficult to predict or assess precisely the effect on water quality of a modification of forcing data (from change in the watershed to global change). A possible approach to overcome this difficulty is numerical modelling. Since the 1970s many water quality and ecological processbased models have been developed (Jorgensen et al., 1996) and the studies of water quality and ecosystem problems with numerical models are increasing rapidly (Cerco \& Cole, 1993; Jorgensen, 1999; Gin et al., 2001; Arhonditsis \& Brett, 2005; Chao et al., 2007). Some well-established threedimensional water quality models have been successfully applied to simulate water quality variables in rivers, lakes, estuaries and ocean environments (Cerco \& Cole, 1995; Luyten et al., 1999; Antenucci et al., 2000; Wool et al., 2001; Hydroqual, 2004; Romero et al., 2004; Danish Hydraulic Institute, 2001; Deltares, 2013).

This type of model has been developed for the Nam Theun 2 (NT2) Reservoir based on the Delft3D code 
(Chanudet et al., submitted). Correct modelling of water quality requires high quality hydrodynamic parameters such as thermal structure, current velocities, local residence time, or the vertical mixing due to density stratification. These parameters influence both the transport (advection and dispersion/diffusion) and the production or transformation of chemical components.

The Delft3D-FLOW model was developed, calibrated and used to simulate the hydrodynamics of the Nam Theun 2 Reservoir (Chanudet et al., 2012). The same model has been used in this study. For water quality, the model is based on the 3D eutrophication model Delft3D-ECO (Smits \& van Beek, 2013). The ECO model has been extended for the NT2 Reservoir. The full model development, set-up and calibration are described in Chanudet et al. (submitted). For the main parameters (dissolved oxygen (DO), Secchi depth, nutrients $\left(\mathrm{NH}_{4}^{+}, \mathrm{NO}_{3}{ }^{-}, \mathrm{PO}_{4}{ }^{3-}\right.$ and $\left.\mathrm{P}_{\text {tot }}\right)$, $\mathrm{SO}_{4}{ }^{2-}$, chlorophyll a, Dissolved Organic Carbon (DOC), $\mathrm{Fe}_{\text {tot }}, \mathrm{CO}_{2}$ and $\mathrm{CH}_{4}$ ), resulting simulations are in good agreement with measurements. Differences between simulated and observed water quality mainly concern the timing and the magnitude of concentration peaks and dips. Parts of these differences are due to inaccuracies in model forcing, in nutrient loads in particular, and to stochastic patchiness of observed reservoir water quality.

In this paper, Delft3D-FLOW and Delft3D-ECO models were considered reliable enough to test the effect of four scenarios on the hydrodynamics and the water quality. In the first scenario, the same average annual hydrodynamic simulation has been repeated as a basis for a 15-year water quality simulation. The objective of this simulation is to assess the medium term evolution of water quality within the reservoir. In a second scenario, the impact of a modification of hydrometeorological forcing data (input discharge and meteorology) is tested on both hydrodynamic and physico-chemical water quality parameters. The third scenario assesses the effect of the initial filling of the Reservoir before the commissioning, leading to a fill and flush effect (no release through the power house for about 2 years). Finally, in the fourth scenario, the impact of a modification of the phosphorous and/or nitrogen concentrations in the incoming rivers on physico-chemical water quality (including chlorophyll a) of the NT2 Reservoir is studied.

\section{MATERIAL AND METHODS}

\subsection{Study system}

The project area is located in the centre of Lao PDR (Khammouane Province) on two sub catchments of the Mekong River. It is a trans-basin project: the reservoir is located on the Nakai Plateau in the Nam Theun watershed, while electricity generation facilities and water release are in the $\mathrm{Xe}$ Bangfai watershed (Fig. 1).

Information about the Nam Theun 2 systems (Reservoir and downstream rivers), technical features and hydrometeorological conditions can be found in Descloux et al. (same issue). The project area is characterised by a subtropical monsoon climate with distinct warm-wet (WW, approximately midJune to mid-October), cool-dry (CD, 


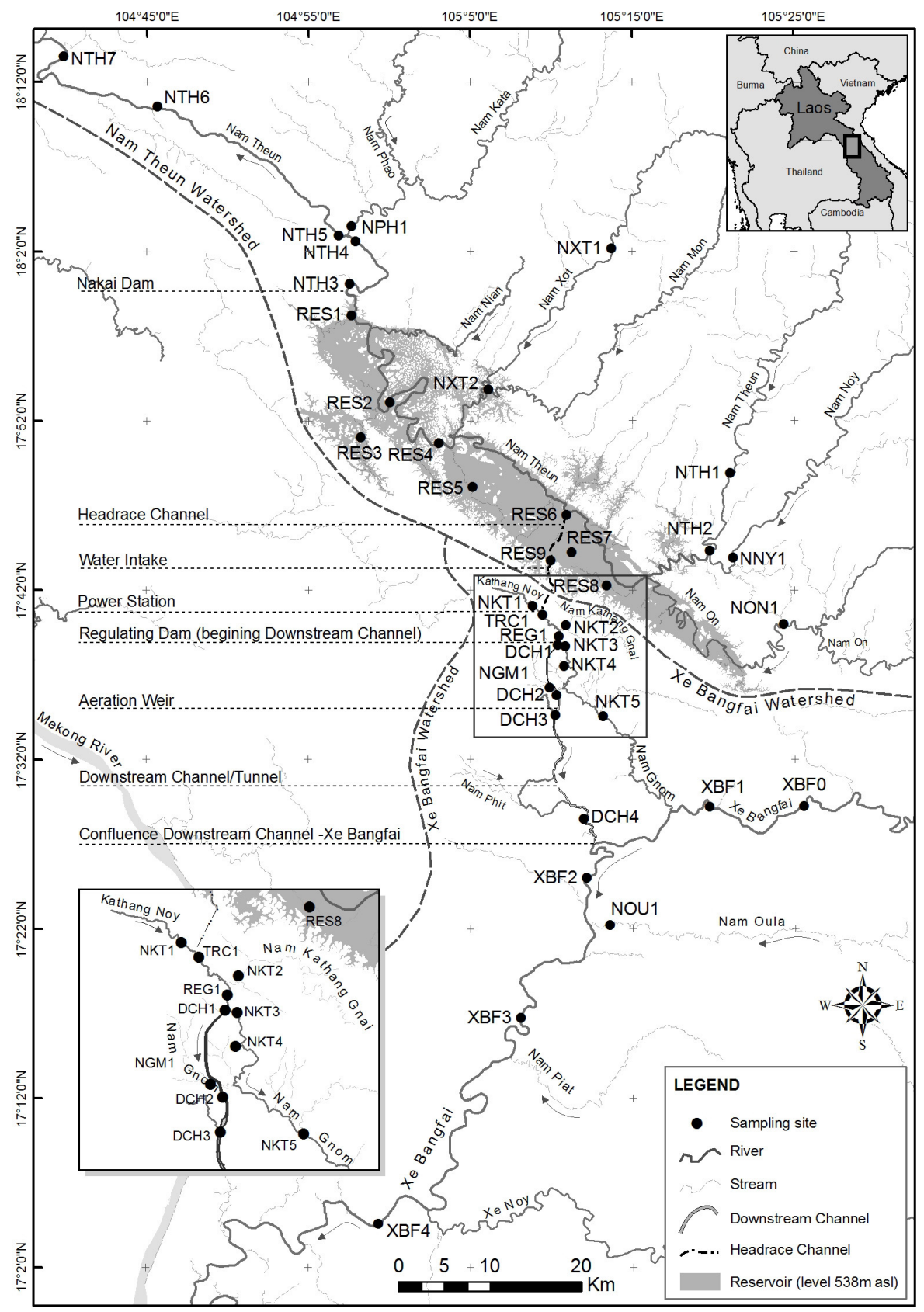

Fig. 1. Location of the NT2 site and monitoring stations (Descloux et al., same issue).

Fig. 1. Cartographie du site de NT2 et des stations de suivi (Descloux et al., same issue). 
approximately mid-October to midFebruary) and warm-dry (WD, approximately mid-February to June) seasons.

The model concerns only the Reservoir. Upstream or downstream rivers and the Downstream Channel are not modelled. This paper focuses mainly on stations located close to Dam (RES1) and close to the Water Intake (RES9) for the implications regarding water quality in downstream systems (rivers and Downstream Channel). Some data for a station located in the upstream zone of the Reservoir (RES8) are also presented.

\subsection{Model description and calibration}

Water quality in the NT2 Reservoir was simulated with Delt3D-ECO (Deltares, 2013). ECO is based on the open source water quality modelling framework D-Water Quality (DELWAQ), that facilitates the selection of substances and processes from a processes library, and has many options for mass conservative numerical integration (Blauw et al., 2009; Deltares, 2013, Smits \& van Beek, 2013). ECO dynamically simulates a set of substances and processes on a 3D computational grid composed of a water grid and a sediment grid that may have the same horizontal resolution. Additional modules have been specifically developed and implemented in ECO for the NT2 Reservoir (vegetation module, inorganic speciation, water-atmosphere exchanges, iron) (Chanudet et al., submitted).

The state variables simulated by ECO and associated processes, as applied for the NT2 Reservoir, are presented in Table I. Figure 2 shows the main interactions between variables in the water and sediment modules.

The decomposition of detrital organic matter is formulated as the mineralization (first-order kinetics) and conversion of six fractions with decreasing degradation rates, describing the entire organic matter cycle in surface water and bed sediment. The decomposition of organic matter requires the consumption of electron acceptors: oxygen, nitrate, iron oxyhydroxide, sulphate and carbon dioxide, which are consumed by bacteria in a specific order.

Phytoplankton is simulated with BLOOM (Los \& Wijsman., 2007; Blauw et al., 2009; Los, 2009; Smits \& van Beek, 2013). In BLOOM the algae species compete within the constraints for available nutrients $(\mathrm{N}, \mathrm{P}, \mathrm{Si})$, available light (energy), the maximum growth rate and the maximum mortality rate (both temperature functions). Linear programming is used as an optimization technique to determine the algae species composition that is best adapted to prevailing environmental conditions.

The computational grid for the water body in the NT2 Reservoir model is a horizontally $8 \times 8$ aggregated version of the hydrodynamic grid model (Chanudet et al., 2012). It results in a grid cell size in the horizontal plane of approximately $1200 \mathrm{~m} \times 1200 \mathrm{~m}$. In the vertical direction, layer thickness is $3.75 \mathrm{~m}$ for the top water layer, less than $2.5 \mathrm{~m}$ for the bottom water layer, $2.5 \mathrm{~m}$ for the intermediate water layers, and increasing with depth 0.5, 4.5, 10, 20 and $65 \mathrm{~cm}$ for the sediment layers. At the deepest point of the Reservoir grid, the depth is $28.75 \mathrm{~m}$. The sediment/soil bed is $1 \mathrm{~m}$ 
Table I. State variables and processes included in the Nam Theun Reservoir water quality model. Table I. Variables d'état et processus inclus dans le modèle qualité d'eau du réservoir de Nam Theun.

\begin{tabular}{|c|c|}
\hline State variable & Process \\
\hline 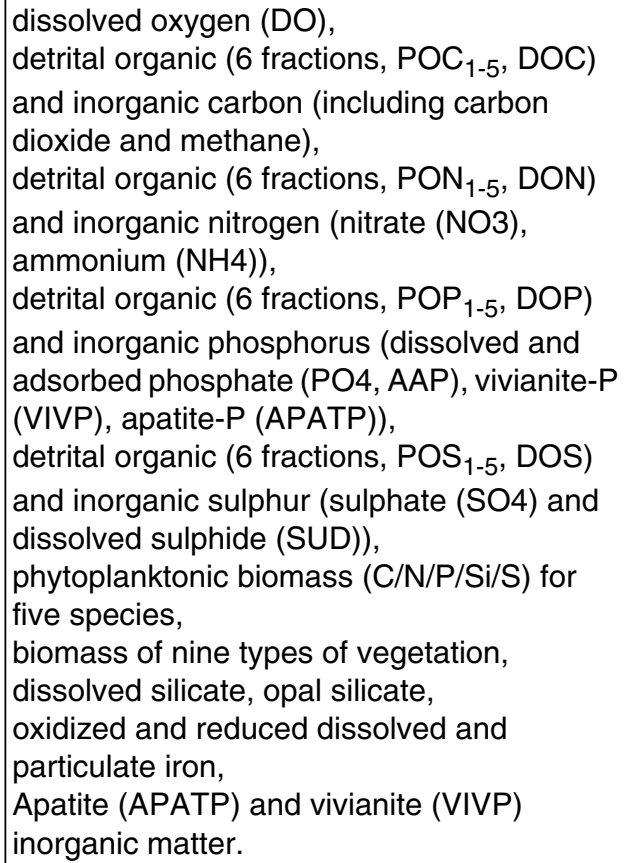 & $\begin{array}{l}\text { exchange of dissolved oxygen, carbon } \\
\text { dioxide and methane with the atmosphere } \\
\text { (reaeration), } \\
\text { consumption of electron acceptors (oxygen, } \\
\text { nitrate, iron(III), sulphate), methanogenesis, } \\
\text { oxidation and ebullition of methane, } \\
\text { speciation of dissolved inorganic carbon, } \\
\text { decomposition of detrital organic matter, } \\
\text { nitrification, denitrification, } \\
\text { adsorption, precipitation of phosphate, } \\
\text { oxidation, precipitation, speciation of } \\
\text { sulphide, } \\
\text { growth and mortality of phytoplankton, } \\
\text { extinction of light, } \\
\text { mortality and re-growth of vegetation } \\
\text { biomass, } \\
\text { dissolution of opal silicate, } \\
\text { oxidation, reduction, precipitation, } \\
\text { speciation of iron, } \\
\text { net settling of particulate components, } \\
\text { mass transport in the sediment. }\end{array}$ \\
\hline
\end{tabular}

deep. The total number of layers in the water column amounts to 12 . The numerical solver applied in the ECO model of the NT2 Reservoir concerns an explicit upwind scheme in the horizontal direction, combined with an implicit in time scheme with central discretization of advection in the vertical direction. The computational time step is 10 minutes. The flow and dispersion fields for the various scenarios with Delft3D-ECO were simulated with the NT2 Delft3D-FLOW hydrodynamic model (Chanudet et al., 2012).

As boundary conditions, the hydrodynamic model requires tributaries discharges and temperature. Forcing data are the meteorological parameters (air temperature, wind speed and direction, solar radiations, humidity and atmospheric pressure) and the Secchi depth (Chanudet et al., 2012, Descloux et al., same issue). For the water quality model, all the simulated substances (Tab. I) need to be defined in the tributaries as boundary conditions. The variables measured (mean and standard deviation between April 2008 and December 2010) and included in the model for calibration/validation are (Chanudet et al., submitted): total suspended solids $\left(8.4 \pm 5.5 \mathrm{mg} \cdot \mathrm{L}^{-1}\right)$, dissolved oxygen $\left(7.2 \pm 1.1 \mathrm{mg} \cdot \mathrm{L}^{-1}\right), \mathrm{NH}_{4}{ }^{+}$ $\left(0.05 \pm 0.03 \mathrm{mg} \mathrm{N} . \mathrm{L}^{-1}\right), \mathrm{NO}_{3}^{-}(0.08 \pm$ $\left.0.04 \mathrm{mg} \mathrm{N}^{-\mathrm{L}^{-1}}\right)$, total $\mathrm{P}(0.03 \pm 0.01 \mathrm{mg}$ P.L $\left.{ }^{-1}\right), \mathrm{SO}_{4}{ }^{2-}\left(0.31 \pm 0.20 \mathrm{mg} \mathrm{S}^{-1} \mathrm{~L}^{-1}\right), \mathrm{Cl}^{-}$ 


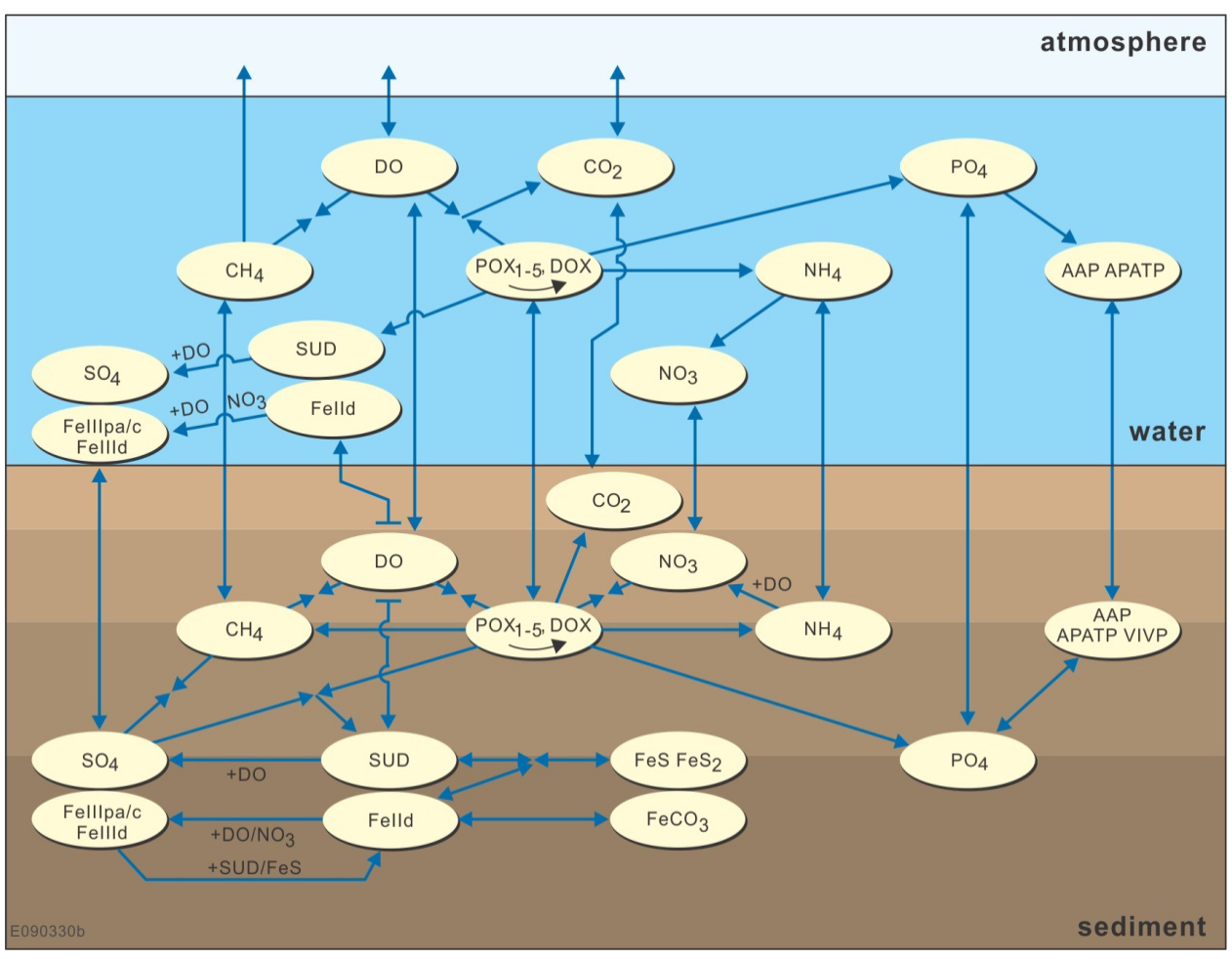

Fig. 2. Schematic overview of the state variables and processes included in ECO. Processes for phytoplankton, vegetation (initial cover and re-growth) and silicate are not included (Chanudet et al., submitted).

Fig. 2. Vue d'ensemble schématique des variables d'états et processus inclus dans ECO. Les processus affectant le phytoplancton, la végétation (couverture initiale et re-croissance) et les silicates ne sont pas inclus (Chanudet et al., submitted).

$\left(1.6 \pm 0.8 \mathrm{mg} \mathrm{Cl} . \mathrm{L}^{-1}\right)$, total Fe $(0.43 \pm$ $\left.0.24 \mathrm{mg} \mathrm{Fe} . \mathrm{L}^{-1}\right)$, total organic carbon $\left(1.43 \pm 0.30 \mathrm{mg} \mathrm{C} . \mathrm{L}^{-1}\right)$ and dissolved organic carbon $\left(1.23 \pm 0.30 \mathrm{mg} \mathrm{C}^{-1} \mathrm{~L}^{-1}\right)$, dissolved $\mathrm{CO}_{2}\left(3.1 \pm 0.5 \mathrm{mg} \mathrm{C}^{-1} \mathrm{~L}^{-1}\right)$, dissolved $\mathrm{CH}_{4}\left(0.01 \pm 0.01 \mathrm{mg} \mathrm{C} . \mathrm{L}^{-1}\right)$. $\mathrm{PO}_{4}{ }^{3-}$ concentration was always below the detection limit $\left(0.01 \mathrm{mg} \mathrm{P.L}^{-1}\right)$ and a constant value of $0.005 \mathrm{mg} \mathrm{P}^{-L^{-1}}$ was chosen. Estimated constant values have been also used for dissolved silicate $\left(4.4 \mathrm{mg} \mathrm{Si.L}{ }^{-1}\right)$. Other substances including organic fractions (N, P and S), adsorbed phosphorus, vivianite, apatite, opaline silicate, dissolved and particulate sulphide have been allocated the concentration of $0.0 \mathrm{mg} \cdot \mathrm{L}^{-1}$.

The calibration and validation of the NT2 model was carried out with data (DO, Secchi depth, nutrients $\left(\mathrm{NH}_{4}{ }^{+}\right.$, $\mathrm{NO}_{3}{ }^{-}, \mathrm{PO}_{4}{ }^{3-}$ and $\mathrm{P}_{\text {tot }}$ ), $\mathrm{SO}_{4}{ }^{2-}$, chlorophyll $a$, dissolved organic carbon (DOC), $\mathrm{Fe}_{\text {tot }}, \mathrm{CO}_{2}, \mathrm{CH}_{4}$ and phytoplankton biomass) acquired between April 2008 and January 2011 (Chanudet et al., same issue). 


\subsection{Definition of the scenarios}

\subsubsection{Medium term evolution of physico-chemical water quality in the NT2 Reservoir}

For this simulation, hydrodynamic and meteorological forcing data and river loading as determined for the period June 2002 to June 2003 were repeated each year for 13 years (Tab. II).

The initial conditions for water quality were taken from simulation results of the calibration phase in June 2011. Details about NT2 Reservoir hydrodynamics during this period (discharges, temperature...) can be found in Chanudet et al. (2012).

\subsubsection{Influence of the hydro-} meteorology on physico-chemical water quality in the NT2 Reservoir

Three different simulations were conducted by using the hydro-meteorological conditions of June 2002 - June 2003 (simulation 1), June 2003 - June 2004 (simulation 2) and June 2005 June 2006 (simulation 3) (Fig. 3). The first simulation, considered as the reference one, corresponded to a hydrology close to an average year (1986-2008). The periods chosen for the second (June 2003 - June 2004) and third (June 2005 - June 2006) simulations were respectively among the driest and the wettest ones observed during the two last decades. The average inflows were $134 \mathrm{~m}^{3} \cdot \mathrm{s}^{-1}$ and $440 \mathrm{~m}^{3} \cdot \mathrm{s}^{-1}$ in 2003-2004 and 2005-2006, respectively $\left(279 \mathrm{~m}^{3} . \mathrm{s}^{-1}\right.$ in $2002-2003$ for the reference simulation) (Fig. 3A). The initial water level ( $1^{\text {st }}$ of June) was
$525.5 \mathrm{~m}$ for the 3 simulations. The initial water temperature was obtained from the result of previous simulations: $26.9,27.0$ and $28.6{ }^{\circ} \mathrm{C}$ for surface water temperature for the three simulations respectively and $19.1,19.1$ and $17.0{ }^{\circ} \mathrm{C}$ for bottom temperature.

During the WW season, the main differences between simulations concerned inflows and water level. The highest discharges in simulations 1 and 3 were above $2500 \mathrm{~m}^{3} \cdot \mathrm{s}^{-1}$ while values did not exceed $800 \mathrm{~m}^{3} . \mathrm{s}^{-1}$ for simulation 2. In average, input discharge during the WW season were 646,261 and $1015 \mathrm{~m}^{3} . \mathrm{s}^{-1}$ for the simulations 1, 2 and 3 respectively. As a consequence, the Reservoir reached the full supply level (538 m) only for simulations 1 and 3 (Fig. 3D). For these two simulations, spillages were observed: $813 \mathrm{~m}^{3} \cdot \mathrm{s}^{-1}$ and $2112 \mathrm{~m}^{3} \cdot \mathrm{s}^{-1}$ maximum in September for simulations 1 and 3, respectively (Fig. 3C). During the "dry" year (simulation 2), the highest water level was only $532.3 \mathrm{~m}$ and no spillage occurred. During the CD and WD seasons, input discharges significantly reduced and were similar between the simulations: 59,58 and $94 \mathrm{~m}^{3} \cdot \mathrm{s}^{-1}$, respectively. Some differences regarding air temperatures can be observed, in particular $s$ and the duration of periods of the lowest temperatures during the CD season (Fig. 3E).

In order to have a relevant assessment of the impact of the hydrology on water quality, simulations did not start from the impoundment (April 2008) but 3 years after (June 2011). As of this date the water quality in Reservoir has become more stable (Tab. II). 


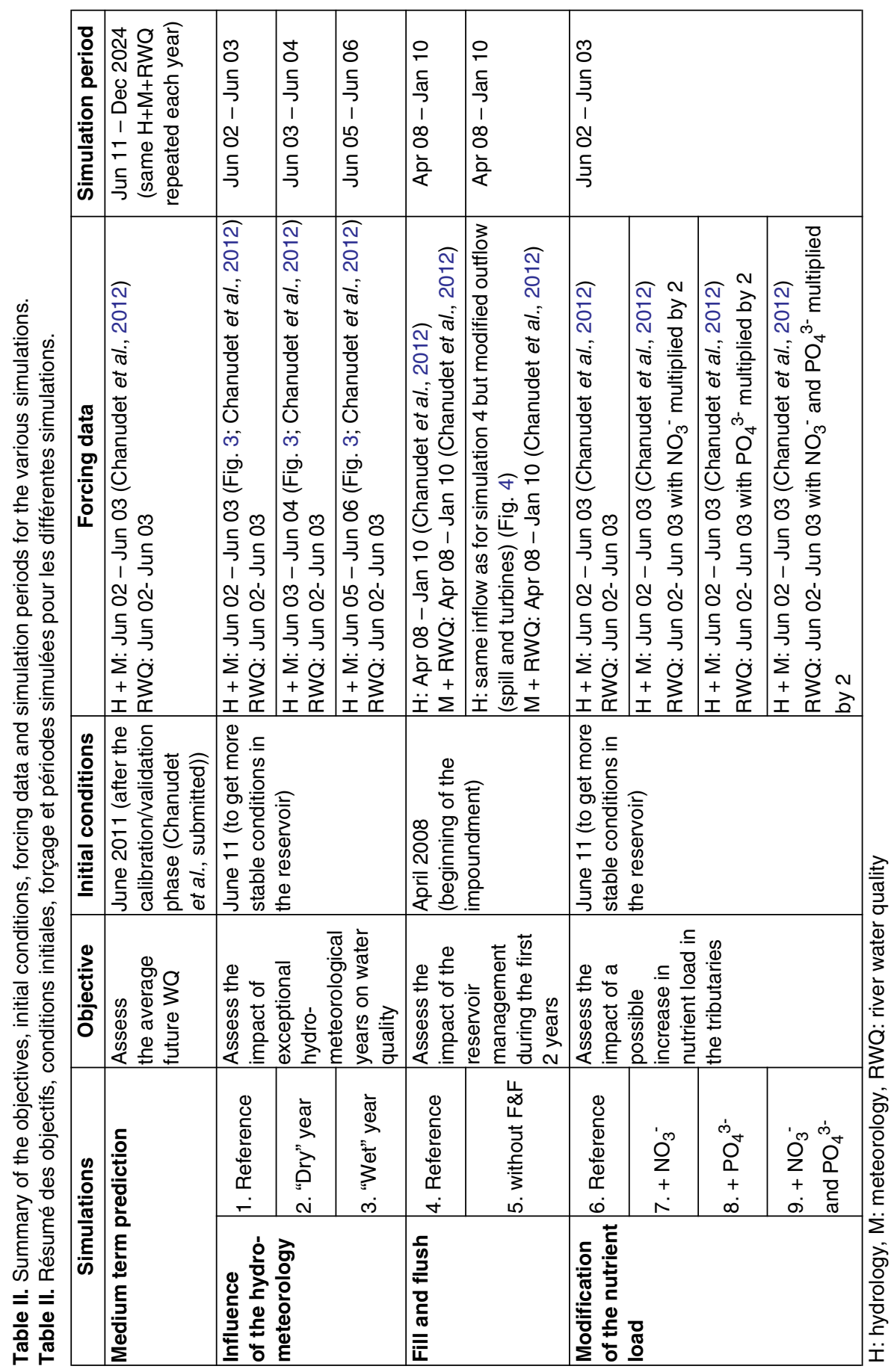




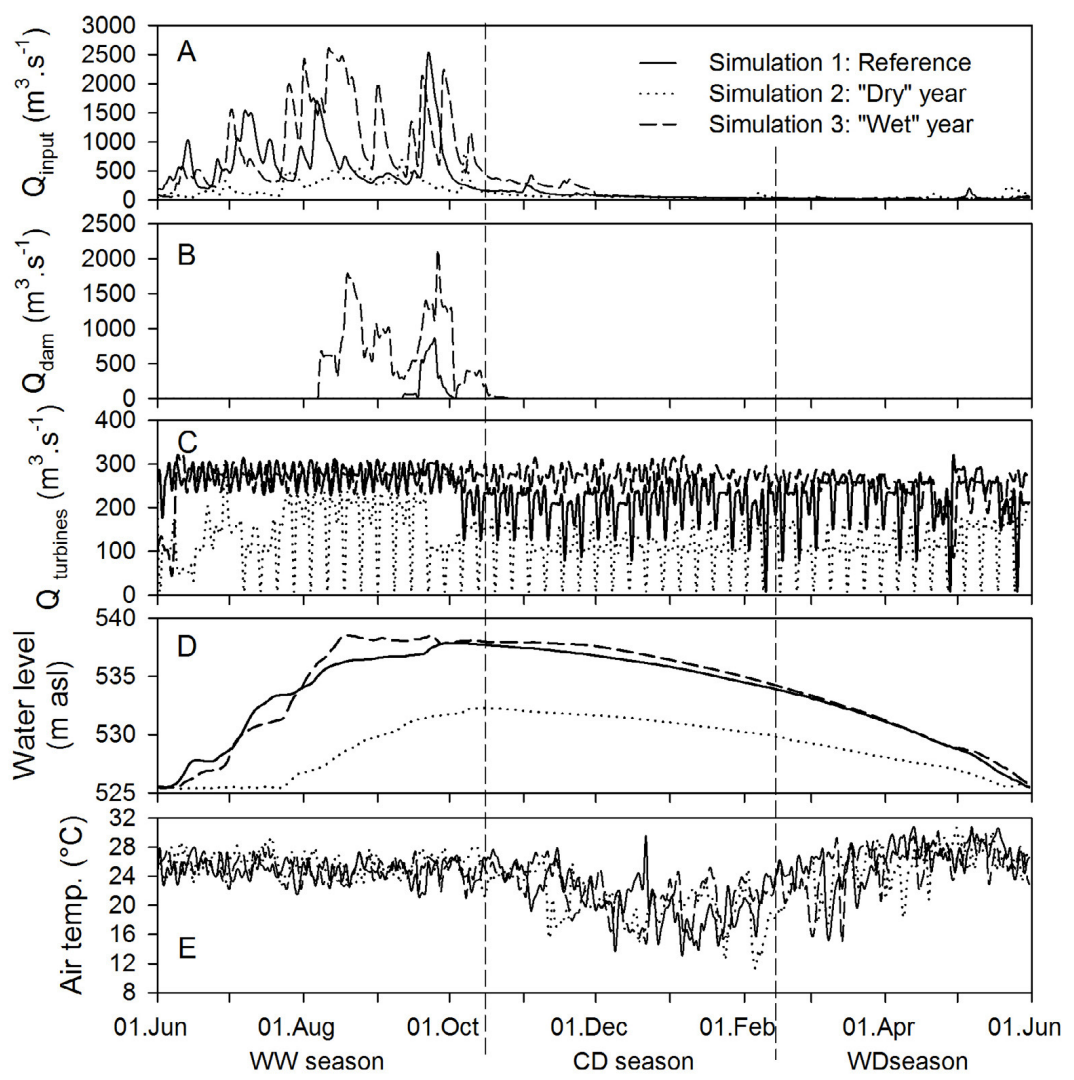

Fig. 3. Tributaries (A), dam (B) and turbine (C) discharges, water level (D) and air temperature (E) for the reference simulation (continuous line), the simulation 2 ("wet" year, dotted line) and simulation 3 ("dry" year, broken line).

Fig. 3. Débits des entrants (A), au barrage (B) et des turbines (C), cote (D) et températures de l'air (E) pour la simulation de référence (ligne continue), la simulation 2 (année « humide ", ligne pointillée) et la simulation 3 (année « sèche », ligne discontinue).

2.3.3 Effect of the fill and flush strategy on physico-chemical water quality in the NT2 Reservoir

Between the first filling (April 2008) and the beginning of significant releases through the power house (March 2010), most of the water coming into the Reservoir was released at the Nakai Dam (riparian release or spillway) into the Nam Theun River. The Reservoir was close to the full supply level (or close to this level) for many months (simulation 4, Fig. 4). During these months, the Reservoir was flushed more than three times (Chanudet et al., same issue). To assess the effect on water quality of this time-lag between the impoundment and the end of 2009, a hypothetical case has been studied 


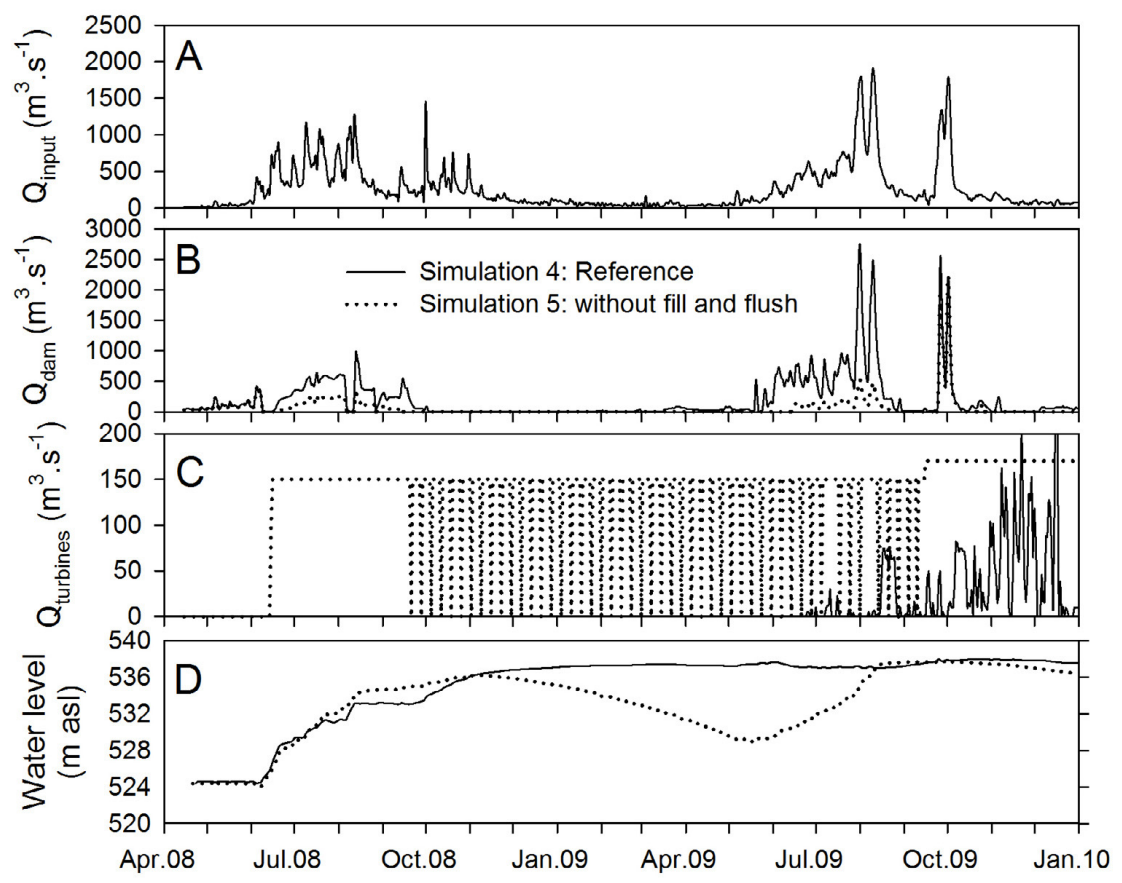

Fig. 4. Tributaries (A), dam (B) and turbine (C) discharges and water level (D) used for the reference simulation 4 (continuous line) and for simulation 5 (without fill and flush, dotted line).

Fig. 4. Débits des entrants (A), au barrage (B) et des turbines (C) et cote (D) utilisés pour la simulation de référence 4 (ligne continue) et la simulation 5 (sans « fill and flush ", ligne pointillée).

during which the normal Reservoir exploitation started on June 2008 (simulation 5). As a consequence, average discharge through the turbines increased significantly from 10.0 to $126.7 \mathrm{~m}^{3} . \mathrm{s}^{-1}$ for the simulated period between simulations 4 and 5 (Fig. 4C). On the contrary discharge at Nakai Dam decreased in simulation 5 as compared to the real case (simulation 4) from 204.3 to $78.8 \mathrm{~m}^{3} . \mathrm{s}^{-1}$ (Fig. 4B). The water level decreased from November 2008 to May 2009 in simulation 5 as observed in normal operation periods after commissioning while it remained stable in simulation 4 (Fig. 4D).
2.3.4 Influence of a modification of the nutrient load in the tributaries on water quality in the NT2 Reservoir

Nutrients $(\mathrm{N}$ and $\mathrm{P})$ concentrations have remained consistently low in the NT2 Reservoir and its tributaries since impoundment (Chanudet et al., same issue). The average $\mathrm{NO}_{3}{ }^{-}$concentration in the incoming rivers was $0.08 \pm$ $0.04 \mathrm{mg} \mathrm{N} . \mathrm{L}^{-1}$ between 2008 and 2013 and the $\mathrm{PO}_{4}{ }^{3-}$ concentration, mostly below the $0.01 \mathrm{mg} \mathrm{P.L^{-1 }}$ (detection level), was estimated around $0.005 \mathrm{mg}$ P. $L^{-1}$. Nutrients in the Reservoir have several origins: (i) release due to the 


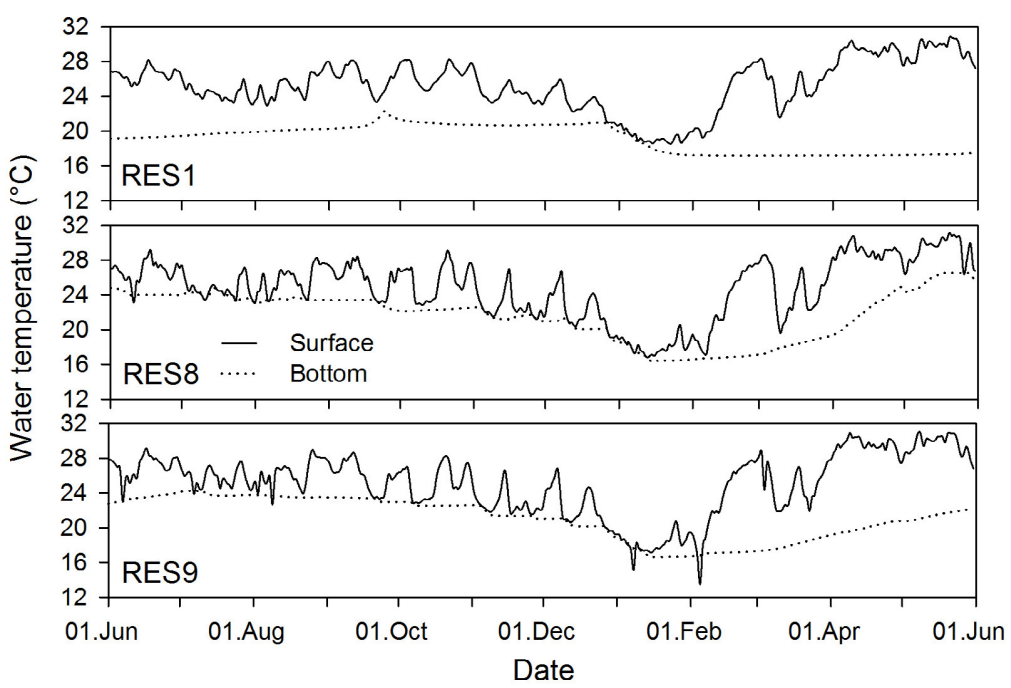

Fig. 5. Surface (continuous line) and bottom (dotted line) water temperatures at RES1, RES8 and RES9 for the simulation used for medium term predictions.

Fig. 5. Température en surface (ligne continue) et au fond (ligne pointillée) à RES1, RES8 et RES9 pour la simulation utilisée pour les prédictions à moyen terme.

degradation of the organic matter present in the vegetation and the soils before impoundment, (ii) input from the rivers into the Reservoir and (iii) recycling within the water column. The contribution of these sources among the overall nutrient load in the Reservoir is likely to change with time (intra- and inter-annual). To assess these changes, three simulations have been done in addition to the reference simulation (simulation 6):

- Increase in $\mathrm{NO}_{3}^{-}$concentration in the river inputs by a factor 2 (simulation 7);

- Increase in $\mathrm{PO}_{4}{ }^{3-}$ concentration in the river inputs by a factor 2 (simulation 8);

- Increase in $\mathrm{NO}_{3}{ }^{-}$and $\mathrm{PO}_{4}{ }^{3-}$ concentrations in the river inputs by a factor 2 (simulation 9).
These simulations were conducted to mimic the potential increase of the nutrient load with a possible future development of the local population (input from sewage), or a change in the watershed land use for instance.

The same hydrodynamics was used for these simulations. As for the hydrodynamics, simulations were conducted after a 3-year calibration period, i.e. in June 2011 ( 3 years after the beginning of the impoundment) (Tab. II).

\section{RESULTS AND DISCUSSION}

\subsection{Medium term prediction}

Simulated surface and bottom water temperatures (Fig. 5) show that for the annual hydro-meteorological 


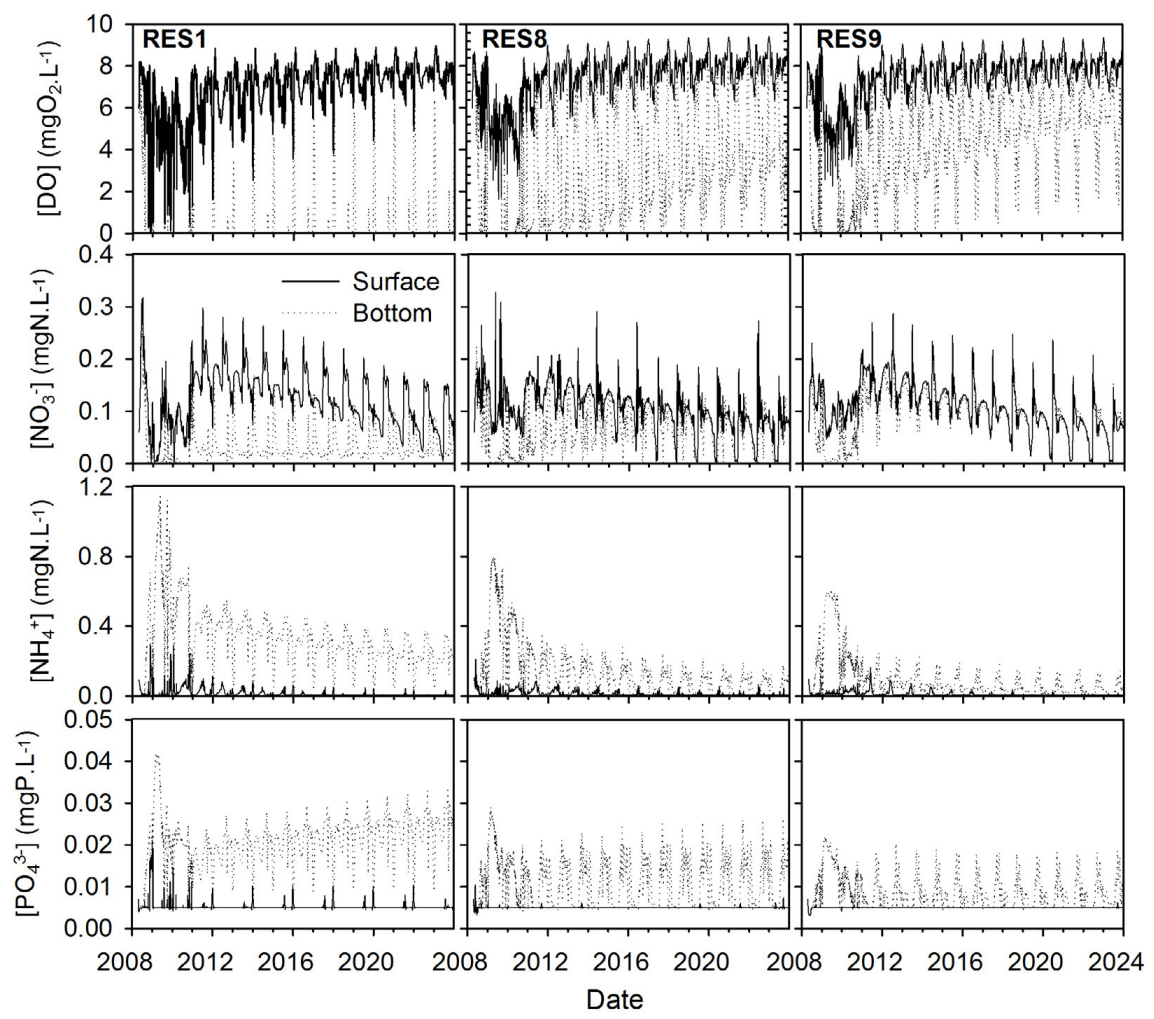

Fig. 6. 15-year simulations of bottom (dotted line) and surface (continuous line) concentrations of dissolved oxygen, $\mathrm{NO}_{3}{ }^{-}, \mathrm{NH}_{4}{ }^{+}$and $\mathrm{PO}_{4}{ }^{3-}$ at RES1 (left hand side), RES8 (middle) and RES9 (right hand side).

Fig. 6. Simulation sur 15 ans des concentrations au fond (ligne pointillée) et en surface (ligne continue) en oxygène dissous, $\mathrm{NO}_{3}{ }^{-}, \mathrm{NH}_{4}{ }^{+}$et $\mathrm{PO}_{4}{ }^{3-}$ à RES1 (gauche), RES8 (milieu) et RES9 (droite).

conditions chosen for the medium terms predictions, the Reservoir overturns in December - January. This is due to the decrease in air temperature (not shown here) during the CD season. The high discharges during the wet season also induce an increase in bottom temperature but it does not reach values calculated in surface. For RES9, between June and February, the thermal stratification is weak or absent.
The evolution of the DO concentrations in the Reservoir for the 15 years following the impoundment (Fig. 6) shows differences in both horizontal and vertical directions. At the seasonal scale, similar patterns are reproduced each year because the same annual hydrodynamic conditions have been applied for each year. At the annual scale, the bottom DO concentration and the duration of the oxic periods during destratification increase slowly 
at RES1. For RES8, bottom DO concentration increases rapidly probably because of the low depth (about $13 \mathrm{~m}$ in the model grid at full supply level) which favours vertical mixing (weak stratification). At RES9, bottom DO concentration increases more rapidly due to the vertical mixing of the water column in this area as a result of the current induced in the Headrace Channel. Surface DO concentrations improve rapidly for the three stations and almost no differences are noticeable 4-5 years after the impoundment, except for short periods during annual Reservoir overturn when the surface DO concentration at RES1 can be below $5 \mathrm{mg} \cdot \mathrm{L}^{-1}(58 \%)$, even after 15 years. The medium term increase in DO concentration can probably be explained by the decrease of mineralisation flux (i.e. organic matter oxic degradation) due to the diminution of the available organic matter as evidenced by its decrease in water and sediment as the initial stock is progressively consumed (Fig. 7). The organic matter export (river outflow) also decreases with time and after a period, the carbon input by the rivers becomes larger than the output by the rivers (Fig. 8). However, the reduction of the output is less obvious as in the sediment because part of the exported organic matter comes from the internal primary production from inorganic carbon.

From 2010, the improvement of DO concentration induces an increase of the $\mathrm{NO}_{3}{ }^{-}$concentrations in the whole water column at the expense of $\mathrm{NH}_{4}{ }^{+}$ which declines rapidly. Then, because of the reduction of nitrogen release from the sediment and dead vegetation into the water, both $\mathrm{NO}_{3}{ }^{-}$and $\mathrm{NH}_{4}{ }^{+}$ concentrations tend to decrease gradually: - $49 \%(p<0.01)$ and $-4 \%(p=$ 0.842 ) for $\mathrm{NO}_{3}^{-}$surface and bottom average annual concentrations and $42 \%(p<0.01)$ and $-73 \%(p<0.001)$ for $\mathrm{NH}_{4}{ }^{+}$(relative difference between 2012 and 2020) for instance at RES1. Seasonal near bottom $\mathrm{NO}_{3}{ }^{-}$peaks correspond with the destratification periods during which oxygen from the surface enhances nitrification. WW season $\mathrm{NO}_{3}{ }^{-}$concentration peaks near the surface arise from high river loads. The better oxygenation conditions, the additional mixing turbulence and the shorter residence time at RES9 induce a lower $\mathrm{NH}_{4}{ }^{+}$concentration and a homogenous vertical profile for $\mathrm{NO}_{3}{ }^{-}$. At RES8, the shorter residence time and the weaker stratification (as compared to RES1) also favour $\mathrm{NO}_{3}{ }^{-}$at the expense of $\mathrm{NH}_{4}{ }^{+}$like at RES9. Whatever the site studied, the contribution of river inputs gradually becomes more important as the bottom load reduces. As for DO, the global reduction of $\mathrm{N}$ species (organic and inorganic) in the water can be explained by the decrease and the stabilization of the concentrations in the sediments as the less refractory organic matter is mineralized (Fig. 7). As a consequence of this decrease, the nitrogen input (tributaries) becomes higher that the river exportation after some years (Fig. 8). The nitrogen excess probably escapes the system through the denitrification process.

Contrary to $\mathrm{NO}_{3}{ }^{-}$, a slight increase in $\mathrm{PO}_{4}{ }^{3-}$ bottom concentration is observed at RES1 (Fig. 6). One possibility to explain this fact is that contrary to nitrogen that can escape the system through nitrification-denitrification processes, $\mathrm{P}$ tends to 


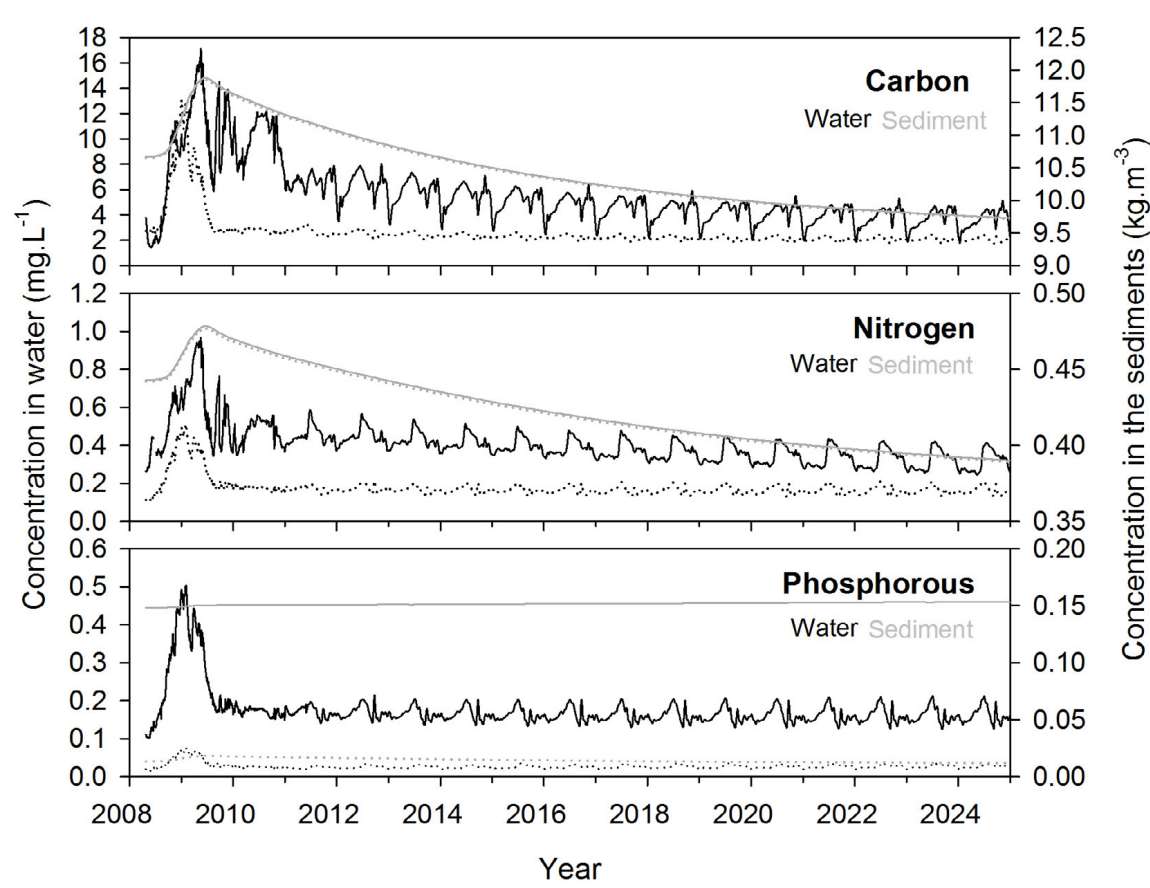

Fig. 7. Medium-term evolution of the organic (dotted line) and total (continuous line) species of carbon, nitrogen and phosphorus concentrations in the water (black) and the sediments (grey) at RES1 (the non bio-available inorganic $\mathrm{P}$ fraction is also considered in the total $\mathrm{P}$ in the sediments, inorganic $\mathrm{C}$ consists here only in $\mathrm{CO}_{2}, \mathrm{CO}_{3}{ }^{2-}, \mathrm{HCO}_{3}{ }^{-}, \mathrm{H}_{2} \mathrm{CO}_{3}$ and $\mathrm{CH}_{4}$ ).

Fig. 7. Évolution à moyen terme des concentrations des espèces organiques (ligne pointillée) et totales (ligne continue) de carbone, d'azote et de phosphore dans l'eau (noir) et les sédiments (gris) à RES1 (la fraction non bio-disponible de $\mathrm{P}$ est également considérée dans le $\mathrm{P}$ total dans les sédiments, le $\mathrm{C}$ inorganique consiste ici seulement en $\mathrm{CO}_{2}, \mathrm{CO}_{3}{ }^{2-}, \mathrm{HCO}_{3}{ }^{-}, \mathrm{H}_{2} \mathrm{CO}_{3}$ et $\mathrm{CH}_{4}$ ).

accumulate in the sediment due to the settling of adsorbed inorganic and detrital organic phosphorus (Fig. 7). At RES1, the residence time is high because there is no significant outflow at the dam and $\mathrm{PO}_{4}{ }^{3-}$ tends to accumulate at the bottom where it is not consumed. At RES9, where the residence time is much lower under normal operation conditions, $\mathrm{PO}_{4}{ }^{3-}$ bottom concentration remains stable with time. In spite of this increase at the bottom, $\mathrm{PO}_{4}{ }^{3-}$ surface concentrations are most of the time (except sometimes at RES1) at the algal uptake threshold imposed on the model $\left(0.005 \mathrm{mg} \mathrm{P}^{-\mathrm{L}^{-1}}\right)$ because of the consumption of phosphate by algae.

\subsection{Influence of the hydro- meteorology on water quality in the NT2 Reservoir}

\subsubsection{Hydrodynamics}

The results of the hydrodynamic simulations for the 3 years show similar 


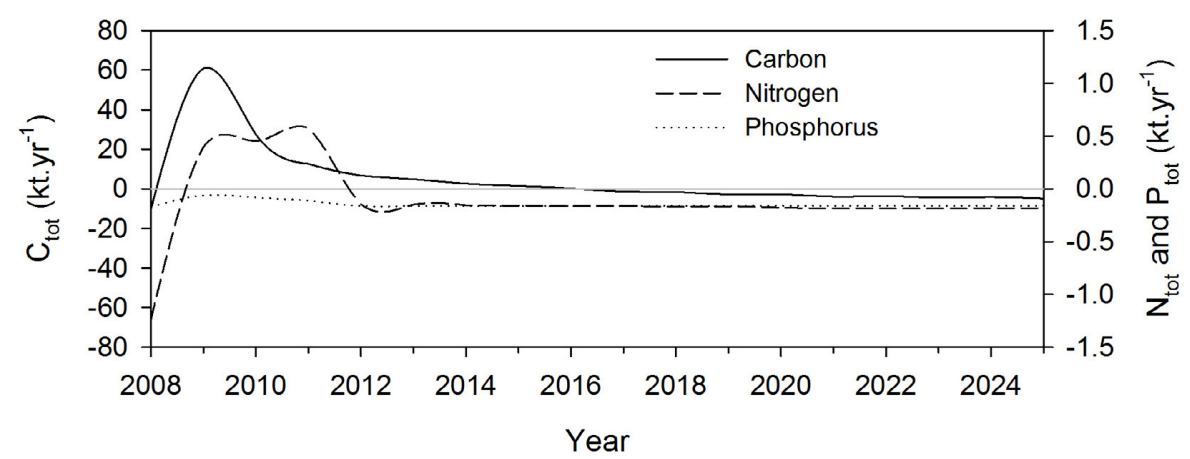

Fig. 8. Medium-term evolution of the differences between river outputs (downstream the dam and the power house) minus tributary inputs of total carbon, total nitrogen and total phosphorus.

Fig. 8. Évolution à moyen terme des différences entre les sorties par les rivières (aval barrage et usine) moins les entrées par les affluents en carbone total, azote total et phosphore total.

seasonal temperature patterns at the annual scale close to the Dam (RES1, Fig. 9A). During the CD season, the whole water column is destratified. Then the stratification starts (WD season) and no clear difference between the years is calculated. Bottom water temperature differs by about $2{ }^{\circ} \mathrm{C}$ between simulations. The most significant difference occurs during the WW season. In August 2005 (simulation 3) the flow-induced destratification is total for some days (no difference between surface and bottom temperatures) while in 2003 (simulation 1) the flowinduced destratification is only partial (about $4{ }^{\circ} \mathrm{C}$ between surface and bottom temperatures). Close to the water intake (RES9, Fig. 9B), the seasonal evolution is the same as described previously but the difference between surface and bottom temperature is lower. The water column is (almost) totally destratified more often and for longer periods than at RES1.

\subsubsection{Physico chemical water quality for simulation 2: "dry" year}

During the WW season, the average DO concentration at RES1 and RES9 tends to decrease between the reference simulation 1 and simulation 2 (Fig. 10, Fig. 11) but the differences are not significant $(p=0.101$ and $p=0.329$ for surface and bottom concentration at RES1 and $p=0.125$ and $p=0.350$ at RES9). During the CD and WD seasons, differences are also erratic and limited except in December when DO concentration increases from $1.6 \mathrm{mg} . \mathrm{L}^{-1}$ (reference) to $8.8 \mathrm{mg} . \mathrm{L}^{-1}$ (simulation 2). During this period, the average DO concentration remains unchanged at the surface $(p=0.275)$ and at the bottom $(p=0.41)$ at RES1 as compared to simulation 1.

Like for DO, significant changes in $\mathrm{NH}_{4}{ }^{+}$concentrations can be observed. During the WW season, surface concentrations tend to increase as compared to 


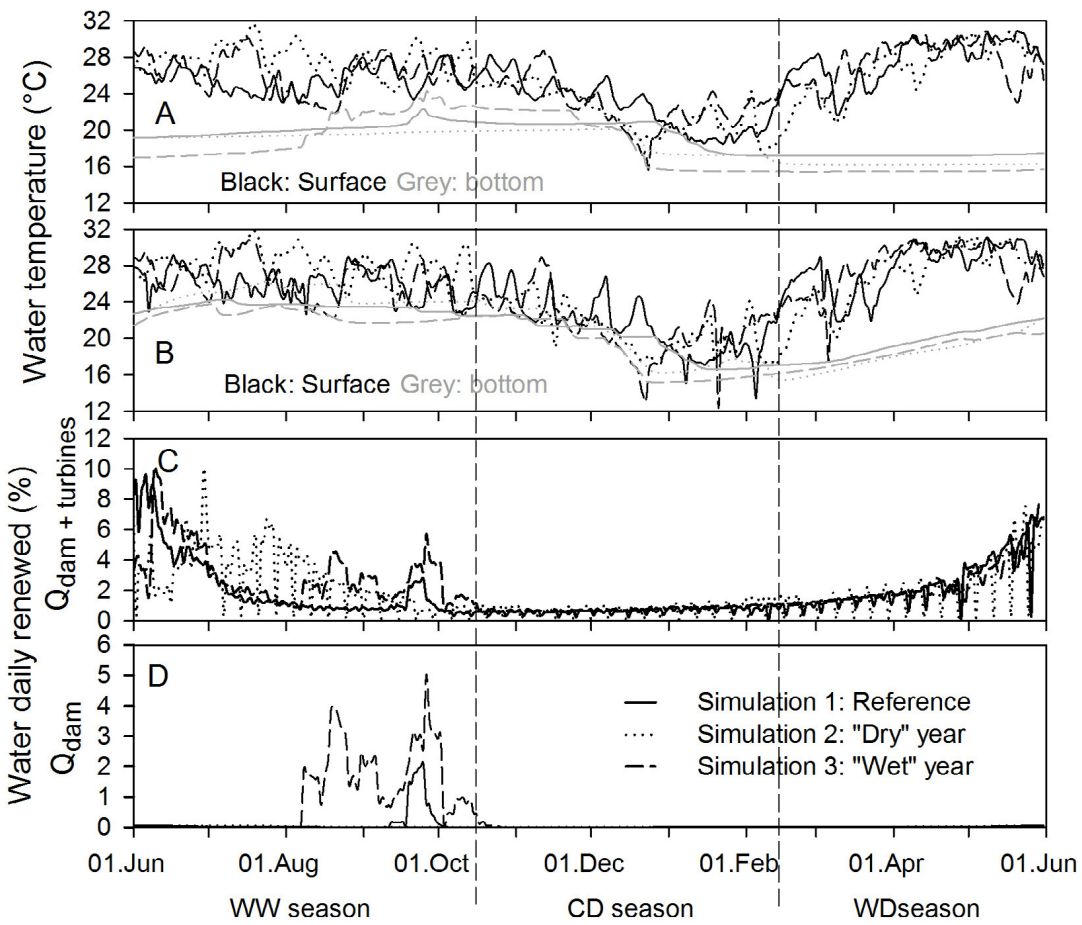

Fig. 9. Water temperature at RES1 (A) and RES9 (B), daily water renewal due to total outflows (dam+ turbine) (C) and to outflow at the dam only (D) for the reference simulation (continuous line), the simulation 2 ("wet" year, dotted line) and simulation 3 ("dry" year, broken line).

Fig. 9. Température de l'eau à RES1 $(A)$ et RES9 $(B)$, taux de renouvellement quotidien de l'eau dû aux débits sortants totaux (barrage + turbines) (C) et aux débits au barrage seuls (D) pour la simulation de référence (ligne continue), la simulation 2 (année " humide », ligne pointillée) et la simulation 3 (année « sèche », ligne discontinue).

simulation 1 (+59\%) while bottom concentrations remain almost unchanged $(+8 \%, p=0.086)$ at RES1 (Fig. 10). During the $C D$ and WD seasons, even if the overall trend is an increase of $\mathrm{NH}_{4}{ }^{+}$concentrations as compared to the reference simulation $(+49 \%$ and $+10 \%$ for surface and bottom concentrations), the evolution is highly variable. For $\mathrm{NO}_{3}{ }^{-}$at RES1 (Fig. 10), the general trend is a decrease as compared to the reference: -8 and $-31 \%$ for surface and bottom concentrations, respectively. On the opposite, $\mathrm{NO}_{3}{ }^{-}$concentrations at RES9 increase (Fig. 11): $+22 \%$ and $+36 \%$ at the surface and the bottom, respectively. $\mathrm{PO}_{4}{ }^{3-}$ simulations are not shown. During the WW season, no differences are observed at RES1: $0 \%$ and $+3 \%(p=0.742)$ for surface and bottom concentrations. At RES9, surface concentration remains constant $(+0 \%)$ as compared to the reference simulation while bottom concentration decreases $(-41 \%, p<0.001)$. During the $\mathrm{CD}$ and WD seasons, no clear trend can 


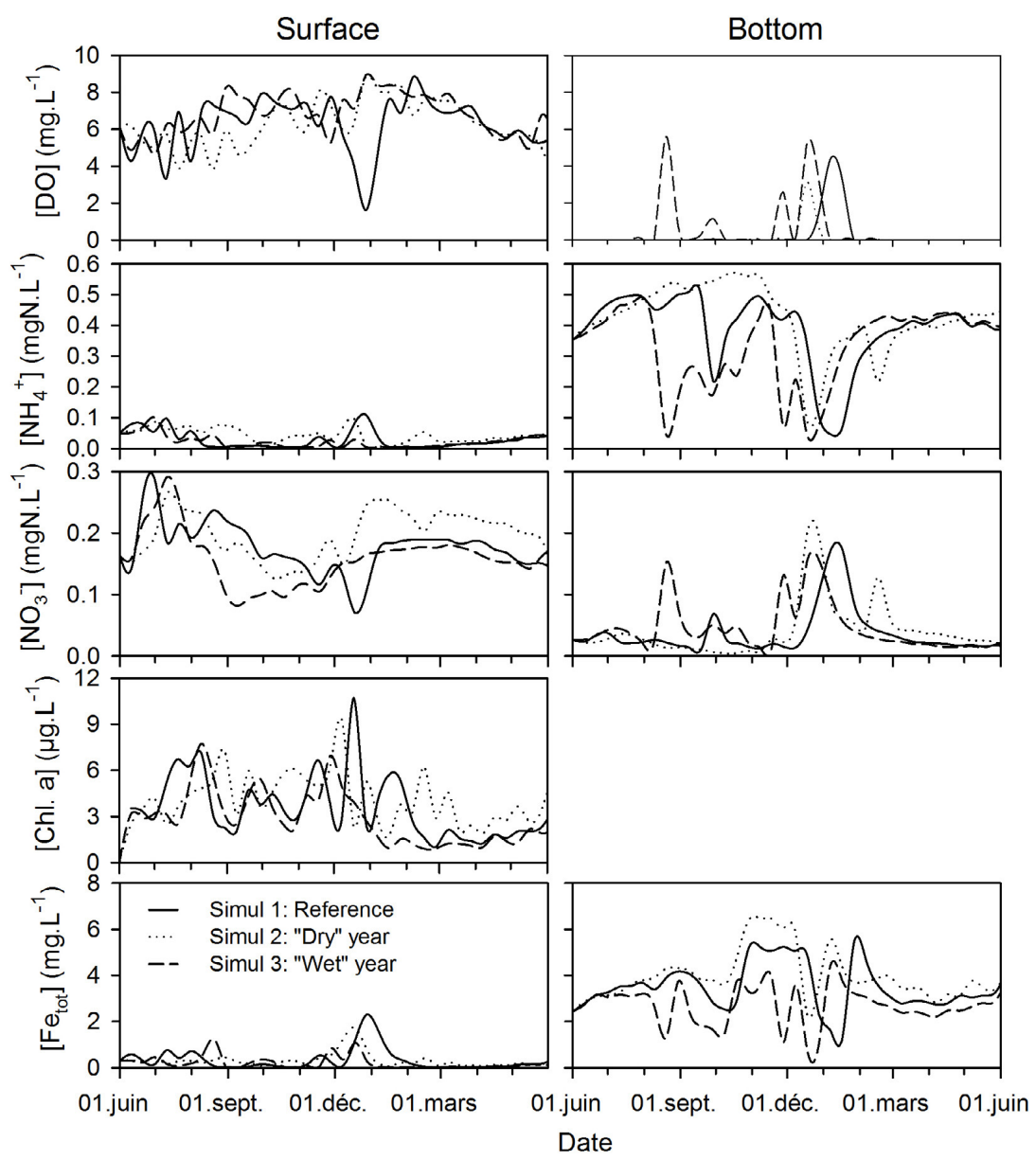

Fig. 10. Surface (left hand side) and bottom (right hand side) concentrations of some physico-chemical parameters in the Reservoir (RES1) for the reference simulation (continuous line), the simulation 2 ("wet" year, dotted line) and simulation 3 ("dry" year, broken line).

Fig. 10. Concentrations de quelques paramètres physico-chimiques en surface (gauche) et au fond (droite) du réservoir (RES1) pour la simulation de référence 1 (ligne continue), la simulation 2 (année " humide ", ligne pointillée) et la simulation 3 (année " sèche », ligne discontinue).

be observed: $-1 \%$ and $+3 \%$ for surface and bottom average concentrations. No clear patterns can be observed for chlorophyll a concentration (Figs. 10 and 11). The dynamics of the phytoplankton, mainly influenced by the $\mathrm{PO}_{4}{ }^{3-}$ concentration in the NT2 Reservoir, is complex and responds rapidly to the slightest changes in hydrodynamics.

The behaviour of total iron is close to that of $\mathrm{NH}_{4}{ }^{+}$(Chanudet et al., same issue). An accumulation is observed during the WW season as compared to 


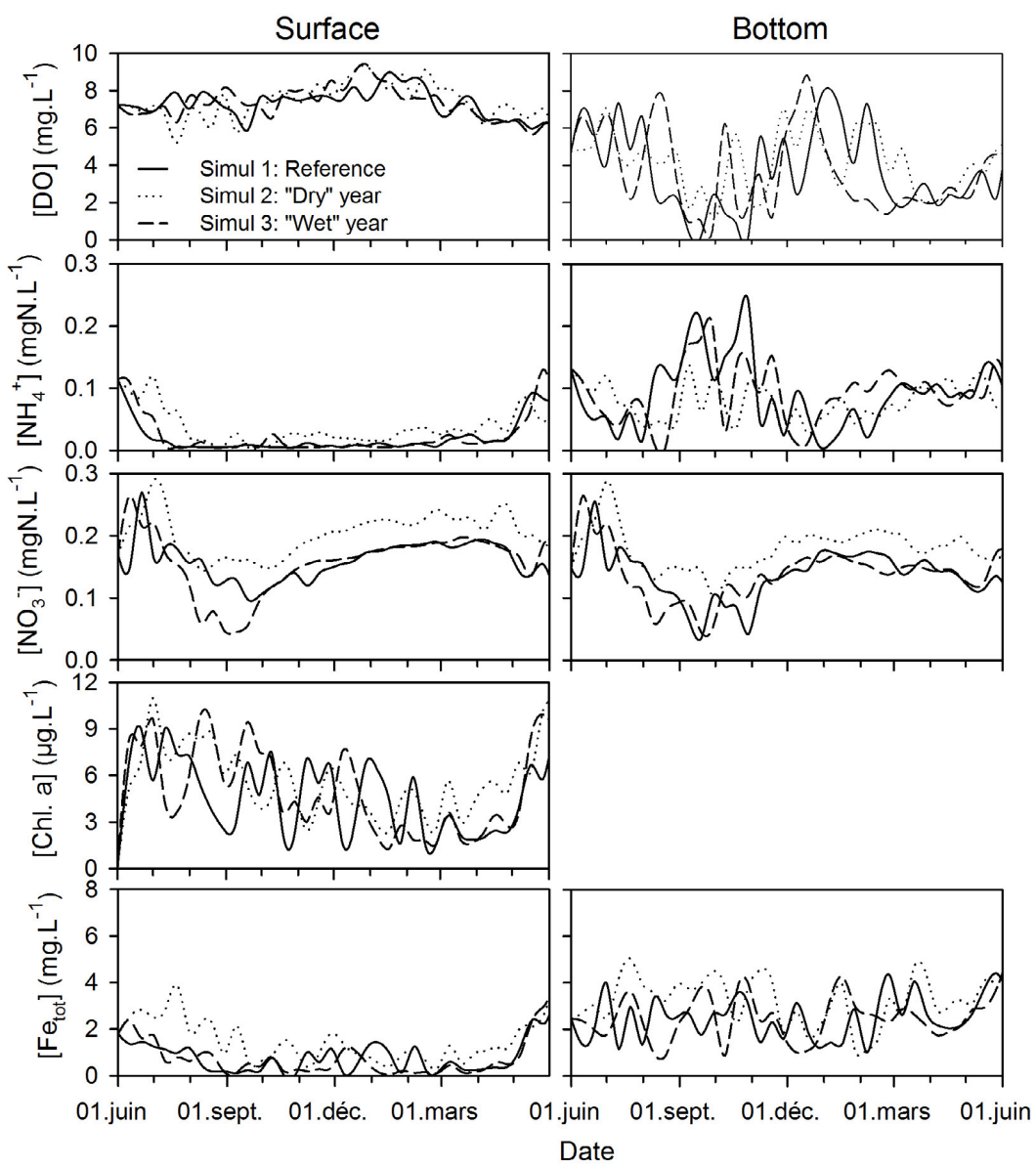

Fig. 11. Surface (left hand side) and bottom (right hand side) concentrations of some physico-chemical parameters in the Reservoir (RES9) for the reference simulation (continuous line), the simulation 2 ("wet" year, dotted line) and simulation 3 ("dry" year, broken line).

Fig. 11. Concentration de quelques paramètres physico-chimiques en surface (gauche) et au fond (droite) du réservoir (RES9) pour la simulation de référence (ligne continue), la simulation 2 (année " humide », ligne pointillée) et la simulation 3 (année " sèche », ligne discontinue).

the reference $(+168 \%$ and $+41 \%$ for surface and bottom concentrations at RES9 for instance). During the CD and WD seasons, the increase is still significant, especially at RES9 $(+42 \%$ and $+21 \%$ for surface and bottom concentrations).

\subsubsection{Physico-chemical water quality for simulation 3: "wet" year}

DO concentrations at the surface during the WW season are close to that calculated for the reference year (Figs. 10 and 11). Close to the Dam 
(RES1), average bottom concentrations are $24 \%$ lower than for the reference simulation. For CD and WD seasons, changes are lower as compared to the reference year $(-14 \%$ and $+3 \%$ for surface and bottom concentrations in average). Like for the "dry" year (simulation 2), the most significant difference occurs in December.

Higher $\mathrm{NO}_{3}{ }^{-}$concentrations during the WW season are simulated at the bottom (Fig. 10) at RES1. At RES9 (Fig. 11), lower surface concentrations are observed as compared to the reference simulation $(-13 \%, p<0.01)$. For $C D$ and WD seasons, mean changes are not significant as compared to the reference year $(+4 \%$ and $-1 \%$ for surface and bottom concentrations). As regard to $\mathrm{PO}_{4}{ }^{3-}$, almost no change occurs at the surface as compared to the reference year. During the WW season, the bottom concentration decreases $(p<0.01)$ for all stations $(-16 \%$ and $-11 \%$ for RES1 and RES9). No significant change can be observed as regard to chlorophyll a concentration.

During the WD season, iron concentrations are close to that measured during the reference year. A decrease is nevertheless observed at RES1 (-23\% at the bottom). During the CD and WD seasons, no clear trend can be observed. On average, concentrations are lower than for the reference simulation: $-27 \%$ and $-9 \%$ for surface and bottom concentrations.

\subsubsection{Effect of the hydrodynamics on physico-chemical water quality}

The impact of the hydro-meteorological conditions on water quality varies spatially between stations close to the Nakai Dam (RES1) and close to the water intake (RES9). At RES1, from August for the "wet" year and from September for the reference simulation, floods induce the input of large quantities of riverine water from the tributaries. The spillage at the dam enhances water renewal for the two simulations in this period (Fig. 9C-D). Consequently, several phenomena are observed at this station for the "wet" year (simulation 3): (i) DO increases at the bottom while reduced compounds $\left(\mathrm{NH}_{4}{ }^{+}, \mathrm{Fe}\right)$ decrease to get closer to the concentration measured in the tributaries, (ii) an homogenisation is observed between surface and bottom water for all the parameters including temperature (Fig. 9A). The opposite is observed for the "dry" year (simulation 2). The absence of spillage precludes any significant water renewal close to the dam. After the spillage (October), water quality evolves similarly for the three simulations: decrease of DO concentration at the bottom and increase of reduced compounds concentration. From December, the differences in the Reservoir hydrodynamics do not depend on the hydrology (same discharges for the three simulations) but rather on the meteorology. For the three simulations, the destratification, as evidenced by surface and bottom temperatures (Fig. 9A), induces a homogenisation of the water column. It occurs mid-December for the "dry" and "wet" years and about two weeks later for the reference simulation. From February, water quality parameters stabilize and become similar for the three simulations.

At RES9 (close to the water intake), the impact of the floods between 
August and October are less significant than close to the dam. This is probably due to the fact that the total water renewal (outputs from the dam and the Power House) is not drastically different between the simulations (Fig. 9C). While this renewal is mainly due to spillage for simulations 3 and 1 , it is almost exclusively supported by the discharge through the turbines (Fig. 9C-D) coupled with a lower Reservoir volume (Fig. 3D) for the "dry" year. Moreover, at this station, the artificial mixing induced by the water intake also explains most of the differences as compared to RES1. This mixing reduces the difference between surface and bottom temperatures (Fig. 9B) and promotes the vertical exchange of chemical compounds (Chanudet et al., same issue). From December, the same phenomenon as in RES1 (in spite of a less pronounced stratification) explains the irregular evolution of water quality parameters for the three simulations.

\subsection{Effect of the fill and flush strategy}

\subsubsection{Hydrodynamics}

Close to the dam (RES1), the lower discharge and water renewal rate in the simulation 5 (without fill and flush, power house commissioning in June 2008) reduces turbulences and vertical exchanges during the WW season as compared to the reference simulation 4 (Fig. 4A). As a consequence, bottom temperature is lower for this simulation (Fig. 12A). During the WD season, the thinner water layer in the simulation 5
(Fig. 4D) does not favour an increase of the bottom temperature (Fig. 12A).

Close to the water intake (RES9), the commissioning of the power house in June 2008 (simulation 5) induces a higher water renewal rate (Fig. 12C-D) and turbulence as compared to the reference simulation 4 . It favours a better vertical homogenisation throughout the year (Chanudet et al., same issue) as evidenced by a higher bottom temperature (Fig. 12B) compared to the reference simulation.

\subsubsection{Physico-chemical water quality}

At RES1, the DO bottom concentration decreases from June 2008 as compared to the reference simulation (2.95 $\mathrm{mgO}_{2} \cdot \mathrm{L}^{-1}$ in average between June and October 2008 for simulation 4 and $1.33 \mathrm{mgO}_{2} \cdot \mathrm{L}^{-1}$ for the same period for simulation 5). In the same time, the concentration of reduced compounds such as $\mathrm{NH}_{4}{ }^{+}$(from 0.09 to $1.17 \mathrm{mgN}^{-1} \mathrm{~L}^{-1}$ ) or $\mathrm{Fe}_{\text {tot }}$ (from 2.39 to $2.96 \mathrm{mgFe} . \mathrm{L}^{-1}$ ) increases at the bottom. The same observation can be done during the 2009 WW season (May-September) for reduced compounds. In both cases, the higher residence time close to the dam in absence of fill and flush as compared to the reference simulation (Fig. 4D) probably explains it. Between October 2008 and May 2009, the discharges at the dam are similar for the two simulations and the water renewal is thus not drastically modified between simulations in spite of the lower Reservoir volume in simulation 5. During this dry period, the differences between the two simulations are low. The smaller 


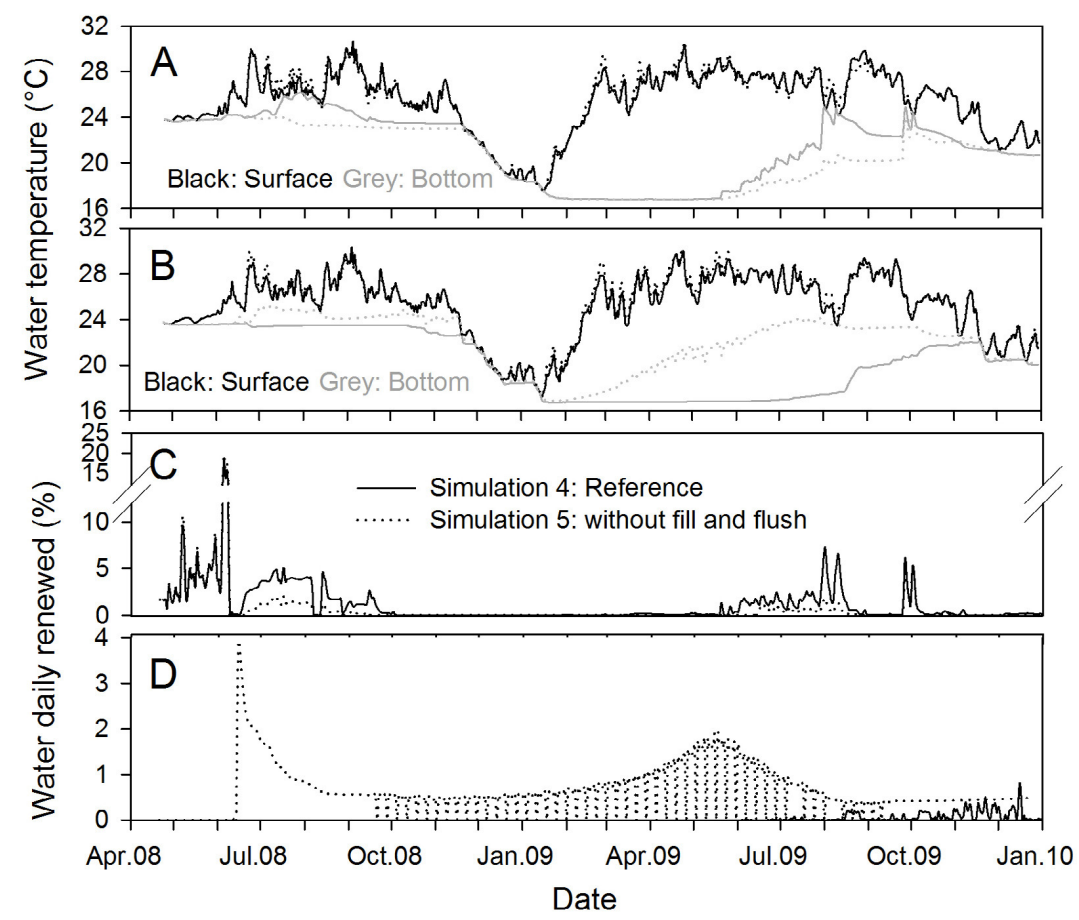

Fig. 12. Surface and bottom temperatures at RES1 (A) and RES9 (B) and daily water renewal due to outflows at the dam (C) and through the turbine (D) for the reference simulation 4 (continuous line) and for simulation 5 (without fill and flush, dotted line).

Fig. 12. Température en surface et au fond à RES1 $(A)$ et RES9 $(B)$ et taux de renouvellement quotidien de l'eau dû aux débits sortants au barrage $(C)$ et aux débits turbinés seuls $(D)$ pour la simulation de référence 4 (ligne continue) et la simulation 5 (sans « fill and flush », ligne pointillée).

water depth for simulation 5 (Fig. 4B) may however explain why surface water quality degrades slightly (less DO and more reduced compounds) in April-May 2009 as compared to the reference simulation: vertical mixing of substances released from the sediment is probably enhanced. Both $\mathrm{Fe}_{\text {tot }}$ surface and bottom concentrations increase gradually during the whole simulated period.

At RES9, the effects of fill and flush are more significant (Fig. 13) than in other parts of the Reservoir. DO concentration increases at the bottom (from 1.00 to $1.84 \mathrm{mgO}_{2} \cdot \mathrm{L}^{-1}$ for simulations 4 and 5 , respectively in average over the whole period), and to a lower extent, at the surface (from 5.94 to $\left.6.22 \mathrm{mgO}_{2} \cdot \mathrm{L}^{-1}\right)$. $\mathrm{NH}_{4}{ }^{+}$concentration also reduces between simulations 4 and 5 from 0.32 to $0.16 \mathrm{mgN} . \mathrm{L}^{-1}$ at the bottom. The average surface concentration remains unchanged $\left(0.01 \mathrm{mgN}^{-L^{-1}}\right)$. Both surface and bottom $\mathrm{NO}_{3}{ }^{-}$concentrations increase as compared to the 


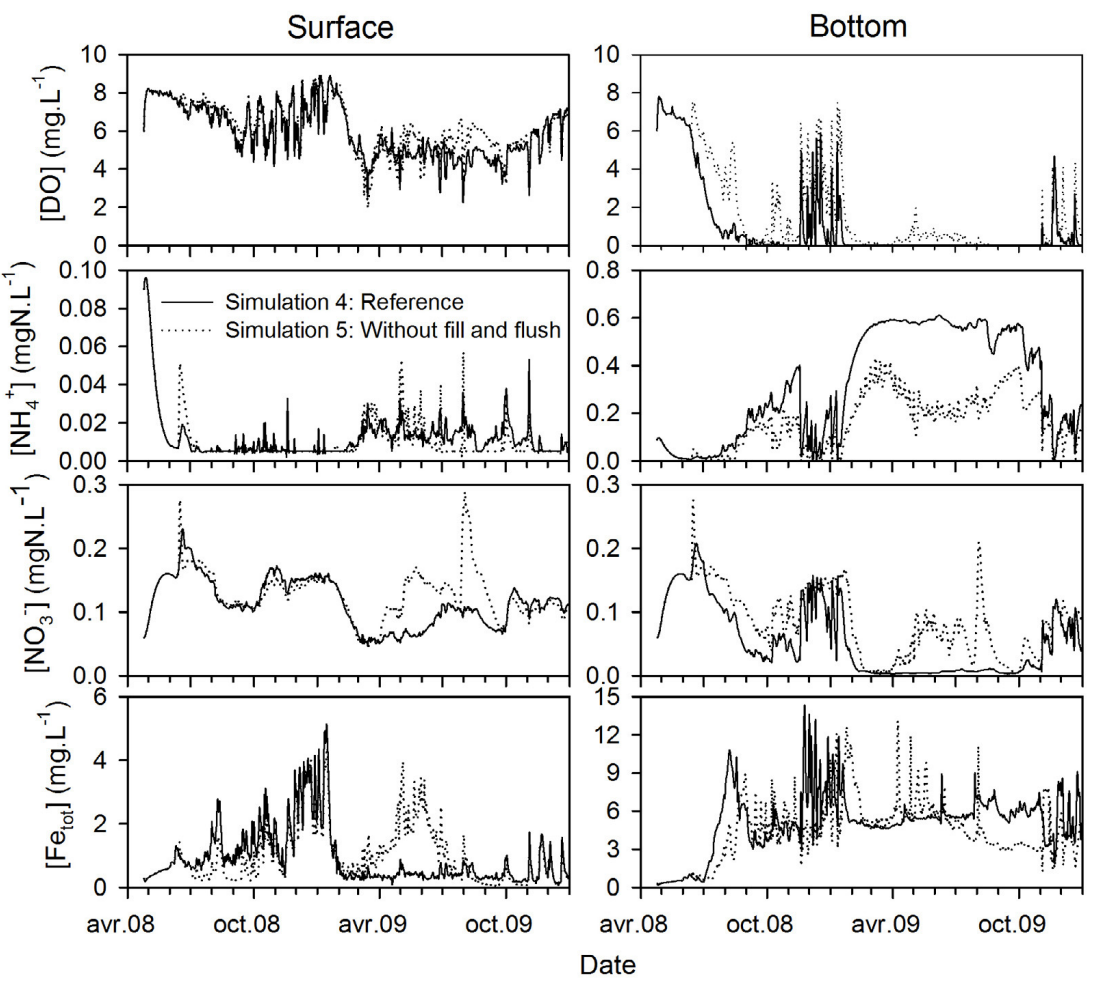

Fig. 13. Surface (left hand side) and bottom (right hand side) concentrations of some physico-chemical parameters in the reservoir (RES9) for the reference simulation 4 (continuous line) and for simulation 5 (without fill and flush, dotted line).

Fig. 13. Concentration de quelques paramètres physico-chimiques en surface (gauche) et au fond (droite) du réservoir (RES9) pour la simulation de référence 4 (ligne continue) et la simulation 5 (sans " fill and flush », ligne pointillée).

reference simulation. The evolution of $\mathrm{Fe}_{\text {tot }}$ is not as clear as the evolution of $\mathrm{NH}_{4}^{+}$. Nevertheless, the average bottom concentration decreases significantly from simulation 4 (9.93 $\mathrm{mgFe}^{-\mathrm{L}^{-1}}$ ) to simulation 5 (4.42 $\left.\mathrm{mgFe} . \mathrm{L}^{-1}\right)$. These observations can probably be explained by: (i) the vertical mixing and (ii) the water renewal rates. Close to the water intake (RES9), turbulences induced a quasi-permanent vertical mixing as shown from temperatures (Fig. 12B). For simulation 5, the commissioning date is June 2008. From this date, the enhanced vertical exchanges favour the homogenisation of the water column. This phenomenon is particularly noticeable between November 2008 and February 2009. In this Reservoir area, high discharges through the water intake imposed in simulation 5 (Fig. 4C) increase the water renewal rate (Fig. 12D) and the input of riverine water coming from the tributaries mainly located in the southeast of the Reservoir (Chanudet et al., 
2012). Moreover, a modification of a water quality parameter, such as DO for instance, may modify the concentration of another one. For instance the highest DO concentration for simulation 5 , especially close to the bottom, may partly explain the highest $\mathrm{NO}_{3}{ }^{-}$ concentration at the expense of $\mathrm{NH}_{4}^{+}$, due to an enhanced nitrification flux.

If the commissioning of the power house had occurred almost immediately after the dam closure (in June 2008, simulation 5), the physico-chemical parameters in the Reservoir close to the dam (RES1) and in the Nam Theun River downstream the dam would not have been drastically modified. The aeration in the downstream river (hollow jet valve for the riparian release and turbulences in the rivers) (Chanudet et al., same issue) would have probably compensated for the faster decrease in DO concentration and the slight increase in reduced compounds. Iron concentration would have probably increased but the loads would have been reduced (Fig. 4B). Downstream of the Power House, changes would have been more significant. In March 2010 physico-chemical parameters have evolved as compared to the first 1.5 years (Chanudet et al., same issue). From March 2010, bottom water at RES9 was almost always oxic with low concentrations of reduced compounds $\left(\left[\mathrm{NH}_{4}^{+}\right]<0.1 \mathrm{mgN} \cdot \mathrm{L}^{-1}\right.$, $\left.\mathrm{Fe}_{\text {tot }}<2 \mathrm{mg} \cdot \mathrm{L}^{-1}\right)$. Water quality downstream the power house reflected this evolution as evidenced by the depth averaged concentrations simulated close to the Water Intake (Fig. 14). If the turbines had started in June 2008, the average $\mathrm{DO}$ concentration in the water column at RES9 (between April
2009 and January 2010) would have been reduced from 2.7 to $1.9 \mathrm{mg} . \mathrm{L}^{-1}$ $(-30 \%)$ as compared to the reference for the same period (but not for the same year). $\mathrm{NO}_{3}{ }^{-}$concentration would have also been reduced from 0.21 to $0.10 \mathrm{mgN} . \mathrm{L}^{-1}$ while the $\mathrm{NH}_{4}{ }^{+}$concentration would have remained constant (0.09 mgN.L-1).

\subsection{Influence of a modification of the nutrient load in the tributaries on water quality in the NT2 Reservoir}

\subsubsection{Simulation 7: doubling $\mathrm{NO}_{3}^{-}$load}

The increase of the $\mathrm{NO}_{3}^{-}$load in the incoming river does not impact the surface and bottom $\mathrm{NH}_{4}^{+}$and $\mathrm{PO}_{4}{ }^{3-}$ concentrations at RES1 (Fig. 15). The $\mathrm{NO}_{3}{ }^{-}$surface concentration in the Reservoir increases only by $9 \%$ $\left(+15 \mu \mathrm{gN} . \mathrm{L}^{-1}\right.$ in average and $+36 \mu \mathrm{gN} . \mathrm{L}^{-}$ ${ }^{1}$ maximum) as compared to the reference simulation $\left(176 \mu \mathrm{gN} . \mathrm{L}^{-1}\right.$ on average). At the bottom, the increase of the $\mathrm{NO}_{3}{ }^{-}$concentration is lower in absolute value: $+5 \mu \mathrm{gN} . \mathrm{L}^{-1}$ on average or $13 \%$ of the concentration calculated for the reference simulation. The increase in $\mathrm{NO}_{3}{ }^{-}$concentration in the Reservoir represents between $6 \%$ and $19 \%$ of the average concentration increase in the tributaries $\left(+80 \mu \mathrm{gN} . \mathrm{L}^{-1}\right)$. This means that in this part of the Reservoir, most of total-N in the water column does not come directly from the tributaries. The diffusion from the sediment and the recycling in the water column are probably the main $\mathrm{N}$ sources.

At RES8 (Fig. 16) and close to the water intake (RES9), the trend is the 


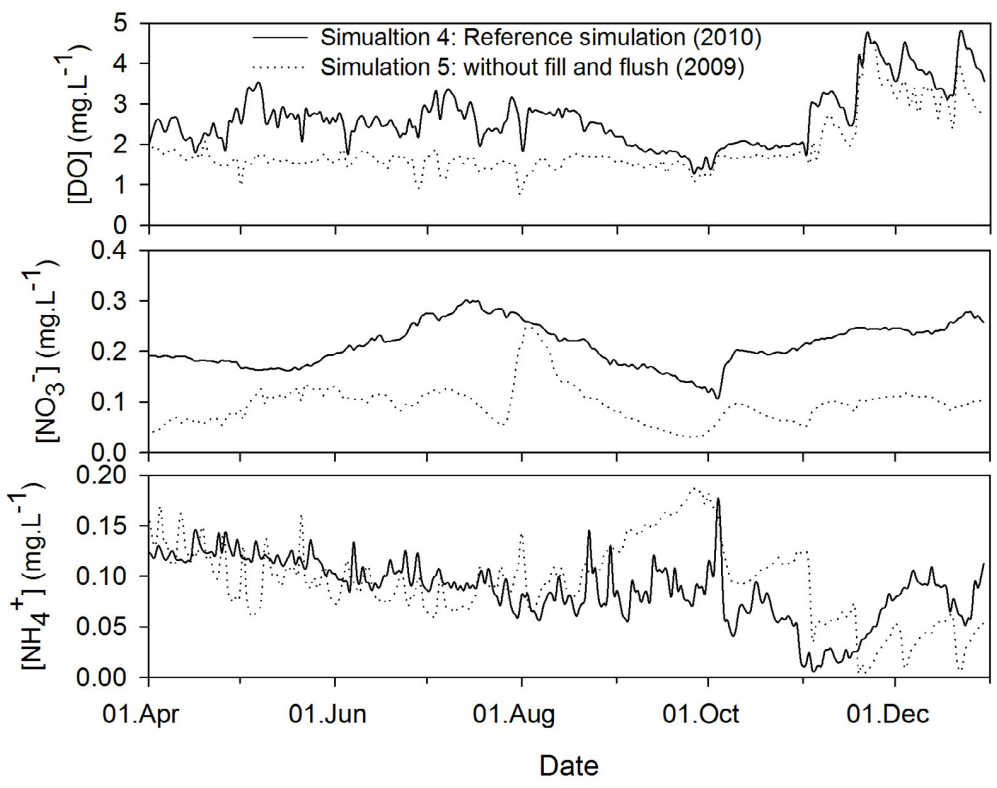

Fig. 14. Depth-averaged concentration of some physico-chemical parameters in the Reservoir close to the water intake (RES9) for the reference simulation 4 (April - December 2010, continuous line) and for simulation 5 (without fill and flush, April - December 2009, dotted line).

Fig. 14. Concentrations moyennées sur la verticale dans le réservoir à proximité de la prise d'eau (RES9) pour la simulation de référence 4 (avril - décembre 2010, ligne continues) et pour la simulation 5 (sans « fill and flush », avril - décembre 2009, ligne pointillée).

same, even if the $\mathrm{NO}_{3}{ }^{-}$gain is slightly higher: $20 \%$ and $17 \%$ at the surface for RES 8 and RES 9 and $28 \%$ and $14 \%$ at the bottom. The phytoplankton activity remains the same in the two simulations (no modification of the chlorophyll a concentration) and the oxygen production is not enhanced as compared to the reference (Tab. III). Moreover, the oxygen demand is not boosted since the concentration of in situ organic matter is stable as well as the reduced compounds concentration $\left(\mathrm{NH}_{4}{ }^{+}\right)$. As a result, the DO concentrations in the two simulations are almost similar.

Five-year mass balance shows that an increase by $100 \%$ of the $\mathrm{NO}_{3}{ }^{-}$inputs results globally in an increase by $18.2 \%$ of the total $\mathrm{N}$ input $(+2.99 \mathrm{ktN})$ as compared to the reference simulation. The output also increases by $8.6 \%$ $(+2.91 \mathrm{ktN})$. It means that almost no $\mathrm{N}$ is stocked in the Reservoir (water + sediment) within five years $(+0.08 \mathrm{ktN})$. No significant change occurs for $P$ species.

\subsubsection{Simulation 8: doubling $\mathrm{PO}_{4}{ }^{3-}$ load}

Doubling the $\mathrm{PO}_{4}{ }^{3-}$ load in the tributaries leads to a limited increase in surface $\mathrm{PO}_{4}{ }^{3-}$ concentration for some periods (July, August and December) at RES1 (Fig. 15). On average, the increase is $0.8 \mu \mathrm{gP} . \mathrm{L}^{-1}$, or $15 \%$ of the 


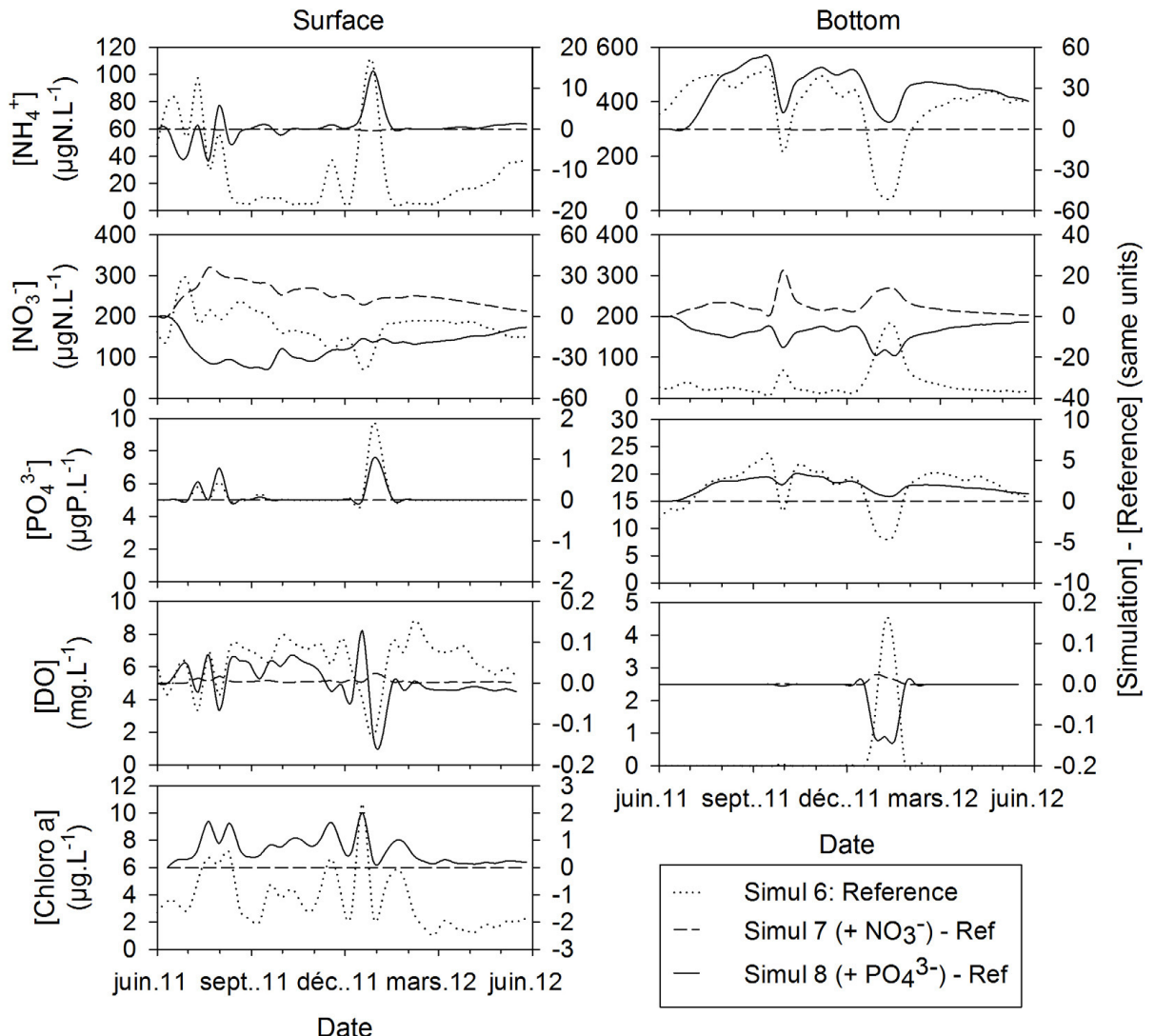

Fig. 15. Surface (left hand side) and bottom (right hand side) concentrations of some physico-chemical parameters in the Reservoir (RES1) for the reference simulation 6 (dotted line). The differences between simulation 7 (increase $\mathrm{NO}_{3}{ }^{-}$river input) and the reference (broken line) and between simulation 8 (increase $\mathrm{PO}_{4}{ }^{3-}$ river input) and the reference (continuous line) are also shown (right hand side scale).

Fig. 15. Concentration de quelques paramètres physico-chimiques en surface (gauche) et au fond (droite) du réservoir (RES1) pour la simulation de référence 6 (ligne pointillée). Les différences entre la simulation 7 (augmentation de l'apport en $\mathrm{NO}_{3}{ }^{-}$par les rivières) et la référence (ligne discontinue) et entre la simulation 8 (augmentation de l'apport en $\mathrm{PO}_{4}{ }^{3-}$ par les rivières) et la référence (ligne continue) sont également présentées (échelle de droite).

average concentration in the reference simulation $\left(5.2 \mu \mathrm{gP} . \mathrm{L}^{-1}\right)$. At RES8 (Fig. 16) and RES9, no difference at the surface is observed as compared to the reference. At the bottom of RES8, the average increase $\left(+1.5 \mu \mathrm{gP} . \mathrm{L}^{-1}\right)$ represents $9 \%$ of the average reference concentration $\left(10.2 \mu \mathrm{gP} . \mathrm{L}^{-1}\right)$ at RES8. At RES9, the average increase at the bottom is $1.0 \mu \mathrm{gP} . \mathrm{L}^{-1}, 13 \%$ of the reference bottom concentration. The same processes as for $\mathrm{NO}_{3}{ }^{-}$can explain the low impact of the concentration in the tributaries. In situ production terms 


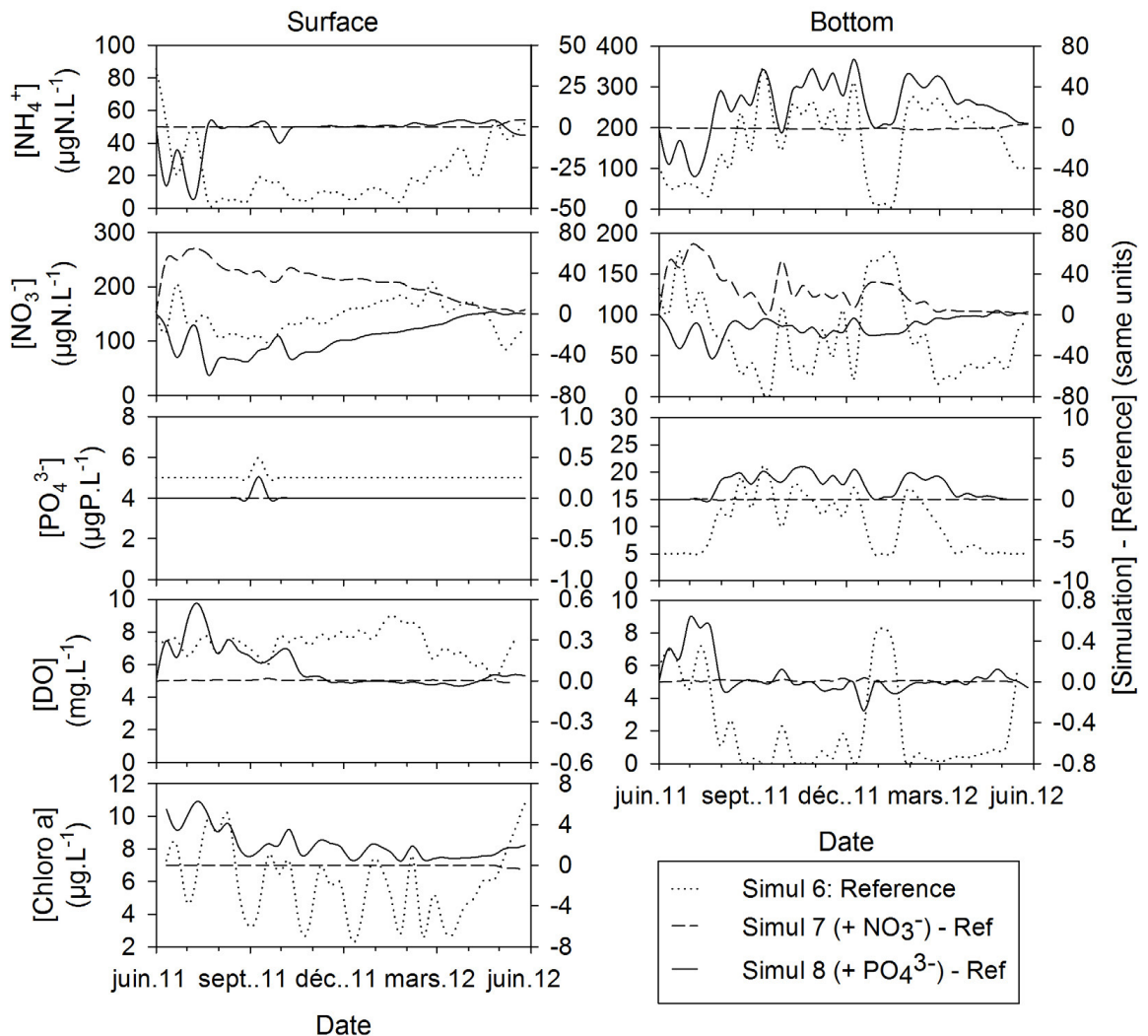

Fig. 16. Surface (left hand side) and bottom (right hand side) concentrations of some physico-chemical parameters in the Reservoir (RES8) for the reference simulation 6 (dotted line). The differences between simulation 7 (increase $\mathrm{NO}_{3}{ }^{-}$river input) and the reference (broken line) and between simulation 8 (increase $\mathrm{PO}_{4}{ }^{3-}$ river input) and the reference (continuous line) are also shown (right hand side scale).

Fig. 16. Concentration de quelques paramètres physico-chimiques en surface (gauche) et au fond (droite) du réservoir (RES8) pour la simulation de référence 6 (ligne pointillée). Les différences entre la simulation 7 (augmentation de l'apport en $\mathrm{NO}_{3}{ }^{-}$par les rivières) et la référence (ligne discontinue) et entre la simulation 8 (augmentation de l'apport en $\mathrm{PO}_{4}{ }^{3-}$ par les rivières) et la référence (ligne continue) sont également présentées (échelle de droite).

(diffusion from the sediments and internal recycling) probably dominate inputs from the incoming rivers.

The average $\mathrm{NH}_{4}{ }^{+}$concentration is increased by $3 \%$ at the surface and $8 \%$ at the bottom at RES1. The impact on $\mathrm{NO}_{3}{ }^{-}$concentration is more significant since concentrations are reduced by $12 \%$ at the surface and $19 \%$ at the bottom. At RES8, the trend is the same: $-15 \%$ at the surface and $-15 \%$ at the bottom. These values are similar at RES9. This decrease of the $\mathrm{NO}_{3}{ }^{-}$concentration can probably be explained 


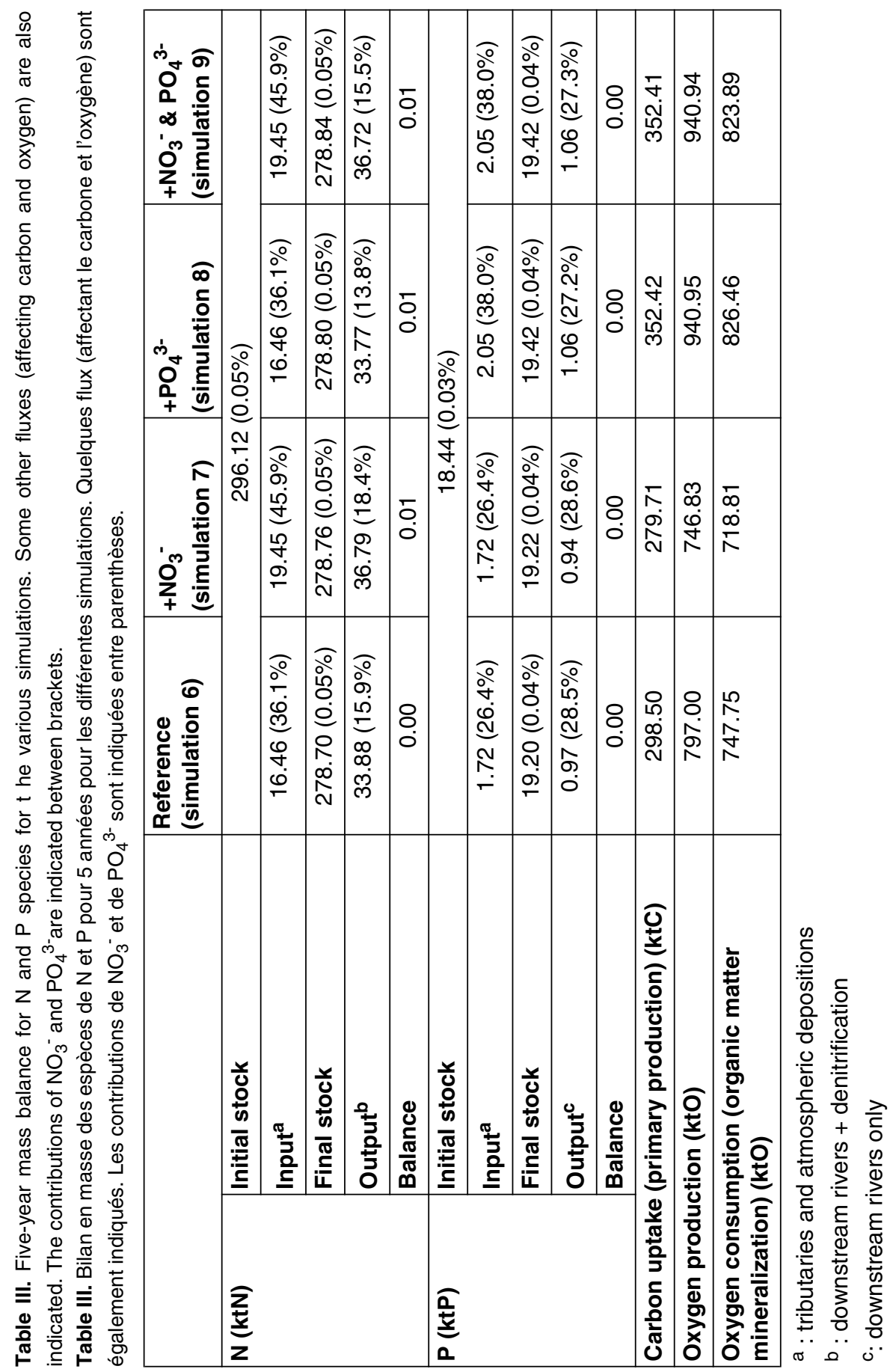


by an enhanced consumption by phytoplankton due to the higher $\mathrm{PO}_{4}{ }^{3-}$ incoming fluxes. At the whole system scale, the five-year mass balance shows that the impact on $\mathrm{N}$ species is low (Tab. III).

$\mathrm{PO}_{4}{ }^{3-}$ concentration remains low since this compound is immediately consumed by phytoplankton, and phosphorus is the main limiting nutrient. Five-year mass balance shows that an increase by $100 \%$ of the $\mathrm{PO}_{4}{ }^{3-}$ inputs results globally in an increase by $19.2 \%$ of the total $P$ input $(+0.33 \mathrm{ktP})$ as compared to the reference simulation. $P$ outputs increase by $9.3 \%(0.09 \mathrm{ktP})$. The final stock (water + sediments) increases by $1 \%$ (+0.24 ktP) (Tab. III).

As compared to the reference simulation, the average concentration of chlorophyll $a$ increased by $0.64 \mu \mathrm{g} . \mathrm{L}^{-1}$ $(+18 \%$ of the reference average concentration) at RES1 (Fig. 15). At RES8 (Fig. 16) and RES9, the fraction of $\mathrm{PO}_{4}{ }^{3-}$ coming from the tributaries (of the total $\mathrm{PO}_{4}^{3-}$ input) is higher than close to the dam because of the lower residence time close to the Water Intake (Chanudet et al., same issue). As a consequence, the increase in $\mathrm{PO}_{4}{ }^{3-}$ load in the tributaries has a higher impact on primary production for these stations. On average, the chlorophyll a concentrations at RES8 and RES9 increased by 2.17 and $1.32 \mu \mathrm{g} . \mathrm{L}^{-1}$ $(+37 \%$ and $+29 \%$ of the reference average concentration), respectively. Mass balance shows that the primary production increases by $18 \%(+53.92 \mathrm{ktC})$ (Tab. III).

The impact on DO is not constant over time. At RES1, the higher photosynthetic activity induces an increase in surface DO concentration from August to November. Then, except in December when the Reservoir overturns, both surface and bottom DO concentrations decrease as compared to the reference simulation. This is probably due to the enhanced oxygen consumption induced by the higher concentration of labile organic matter produced in the Reservoir by phytoplankton as evidenced by the higher chlorophyll $a$ concentration. At RES8, most of the time, the impact is an increase of the DO concentration, especially at the surface and from June to December. At the whole system scale (water + sediments), the increase in oxygen production $(+143.95 \mathrm{ktO})$ is balanced by an increase in oxygen consumption by mineralisation (+ $78.71 \mathrm{ktO})$ (Tab. III).

\subsubsection{Simulation 9: doubling $\mathrm{NO}_{3}^{-}$ and $\mathrm{PO}_{4}{ }^{3-}$ load}

The cumulated increases of $\mathrm{NO}_{3}{ }^{-}$ and $\mathrm{PO}_{4}{ }^{3-}$ concentrations in the tributaries (simulation 9) produce the same results as seen for the increase of $\mathrm{PO}_{4}{ }^{3-}$ only (simulation 8) (Tab. III). It confirms that the NT2 Reservoir is $P$ limited, and is sensitive to any additional $\mathrm{P}$ input.

\section{CONCLUSION}

Four different types of scenario simulations have been performed with the water quality model of the Nam Theun 2 Reservoir. These simulations show the capabilities of the model to answer questions related to natural or human forcing in such a system. The conclusions for each scenario type are presented below. 
1. Prediction of medium term evolution considering constant hydrodynamic conditions. A 15-year simulation confirms the observation made during the first five years after impoundment. The DO concentration will probably continue to increase in the water column associated with a decrease of the concentrations of reduced compounds. However, even after 15 years, the simulation shows that the bottom water in the Reservoir close to the dam may remain anoxic most of the time (assuming yearly repeated hydrodynamics with a yearly Reservoir mixing).

2. Assessment of the effects of the natural inter-annual variability of hydrometeorological conditions on water quality in the Reservoir. At the annual scale, , the duration and the magnitude of the wet season have an influence on the water quality in the whole Reservoir and spatial heterogeneities are observed. The water level at the moment of a flood event also affects the Reservoir water quality. If the water level is low, a flood will renew a larger fraction of the water in the reservoir. In addition to differences due to in and outflows, meteorological parameters could also drastically modify water quality by changing the stratification conditions and thus the vertical exchanges. However, simulations show that differences are mainly perceptible during short periods of time and the annual evolution is similar in the simulations.

3. Assessment of the effects of the management of the Reservoir on water quality. Simulations have been done to quantify the effect of an earlier commissioning on water quality in the Reservoir and in downstream rivers. Close to the dam (RES1), physico-chemical water quality would not have changed drastically in spite of a lower water renewal rate due to the reduction of discharges at the dam as compared to how it evolved in reality. At the water intake (RES9), and consequently in the downstream system (NT2 Downstream Channel and Xe Bangfai River), some modifications of the water quality would have occurred. Simulations show that if the commissioning had occurred immediately after the impoundment, the physico-chemistry of the water released downstream from the power house would have been degraded (only one year simulated) with a decrease of the DO concentration and an increase of reduced compounds.

4. Assessment of the impacts of a modification of the watershed (population, land use...) on water quality in the Reservoir. The sensitivity of the model to an increase of the nutrients $\left(\mathrm{NO}_{3}{ }^{-}\right.$or/and $\left.\mathrm{PO}_{4}{ }^{3-}\right)$ load from the tributaries of the Reservoir has been quantified. Doubling the $\mathrm{NO}_{3}{ }^{-}$load in the rivers has almost no effect on water quality. On the contrary, an additional input of $\mathrm{PO}_{4}{ }^{3-}$ induces changes of the concentrations of both $\mathrm{N}$ and $\mathrm{P}$ species. Such a modification of the nutrient balance enhances photosynthetic activity, because phosphorus is the main limiting nutrient for phytoplankton. This increase is more significant close to the Intake where 
the influence of the load from the tributaries is higher than close to the dam. The enhancement of primary production affects DO through two opposite ways: (i) a direct increase near the surface due to the oxygen production during photosynthesis and (ii) a decrease near the bottom due to the oxygen consumption for the mineralization of the newly produced organic matter.

From the results of the scenario simulations, it appears that the model is an efficient tool for hydrodynamic and water quality studies in the NT2 Reservoir.

\section{ACKNOWLEDGEMENTS}

This research has been conducted at the Aquatic Environment Laboratory of Nam Theun 2 Power Company in Lao PDR whose Shareholders are Électricité de France, Lao Holding State Enterprise and Electricity Generating Public Company Limited of Thailand.

We are also grateful to the Nam Theun 2 Power Company for logistical support and to all the members of the Aquatic Environment Laboratory (AEL) of the Nam Theun 2 project for sampling and analysis.

\section{REFERENCES}

Antenucci J.P., Imberger J. \& Saggio A., 2000. Seasonal evolution of the basin-scale internal wave field in a large stratified lake. Limnol. Oceanogr. $45: 1621-1638$.

Arhonditsis G.B. \& Brett M.T., 2005. Eutrophication model for Lake Washington (USA): Part I. Model description and sensitivity analysis. Ecol. Model. 187 : 140-178.

Blauw A.N., Los, F.J. Bokhorst M. \& Erftemeijer P.L.A., 2009. GEM: a generic ecological model for estuaries and coastal waters. Hydrobiologia 618 : 175198.

Cerco C. \& Cole T., 1993. Three Dimensional Eutrophication Model of Chesapeake Bay. J. Environ. Eng. 119 : 10061025.

Cerco C.F. \& Cole T., 1995. User's Guide to the CE-QUAL-ICM: Three-Dimensional Eutrophication Model. Technical Report EL-95e1 5. Vicksburg: U.S. Army Corps of Engineers.

Chanudet V., Fabre V. \& van der Kaaij T., 2012. Application of a three-dimensional hydrodynamic model to the Nam Theun 2 Reservoir (Lao PDR). J. Great Lakes Res. 38 : 260-269.

Chanudet V., Guédant P., Rode W., Godon A., Guérin F., Serça D., Deshmukh C. \& Descloux S. Evolution of the physicochemical water quality in the Nam Theun 2 Reservoir and downstream rivers for the first 5 years after impoundment. Hydroécol. Appl. 19 (same issue).

Chanudet V., Smits J., van Beek J., Boderie P., Guérin F., Serça D., Deshmukh C. \& Descloux S. Application of a threedimensional water quality model to the Nam Theun 2 Reservoir (Lao PDR), submitted.

Chao X., Jia Y., Shields Jr F., Wang S.S.Y. \& Cooper C.M., 2007. Numerical modeling of water quality and sediment related processes. Ecol. Model. 201 : 385397.

Danish Hydraulic Institute, 2001. MIKE 3 Estuarine and Coastal Hydraulics and Oceanography - Short Description. Horsholm: DHI Water \& Environment, $32 \mathrm{p}$. 
Deltares, 2013. D-Water Quality, Water quality and aquatic ecology modelling suite. User Manual - Water Quality and Aquatic Ecology, and Technical Reference Manual - Processes Library Description. Delft, The Netherlands: Deltares.

Descloux S., Guedant P., Phommachanh D. \& Luthi $R$. Main features of the Nam Theun 2 hydroelectric project (Lao PDR) and the associated environmental monitoring programme. Hydroécol. Appl. 19 (same issue).

Gin K., Zhang Q., Chan E. \& Chou L., 2001. Three-Dimensional Ecological-Eutrophication Model for Singapore. J. Environ. Eng. 127 : 928-937.

Hydroqual, 2004. User's Guide for RCA, Release 3.0. New Jersey: Hydroqual, Inc.

Jorgensen S.E., 1999. State-of-the-art of ecological modelling with emphasis on development of structural dynamic models. Ecol. Model. 120 : 75-96.

Jorgensen S.E., Halling-Sørensen B. \& Nielsen S.N., 1996. Handbook of Environmental and Ecological Modeling. Boca Raton: Lewis Publisher, 672 p.

Los F.J., 2009. Eco-hydrodynamic modelling of primary production in coastal waters and lakes using BLOOM. PhD Thesis Wageningen University (ISBN 978-90-8585-329-9; ext. version IOS
Press BV, Amsterdam, ISBN 978-158603-987-5), $276 \mathrm{p}$

Los F.J. \& Wijsman J.W.M., 2007. Application of a validated primary production model (BLOOM) as a screening tool for marine, coastal and transitional waters. J. Mar. Syst. 64 : 201-215.

Luyten P.J., Jones J.E., Proctor R., Tabor A., Tett P. \& Wild-Allen K., 1999. COHERENS - A Coupled HydrodynamicalEcological Model for Regional and Shelf Seas - User Documentation. MAS3CT97-0088. MUMM Report, Management Unit of the Mathematical Models of the North Sea, $914 \mathrm{p}$.

Romero J.R., Antenucci J.P. \& Imberger J., 2004. One- and three-dimensional biogeochemical simulations of two differing reservoirs. Ecol. Model. 174 : 143-160.

Smits J.G.S. \& van Beek J.K.L., 2013. ECO: A Generic Eutrophication Model Including Comprehensive Sediment-Water Interaction. PLOS ONE, doi:10.1371/ journal.pone.0068104.

Stumm W. \& Morgan J.J., 1996. Aquatic chemistry (third edition). New York: John Wiley \& Sons, Inc., $1022 \mathrm{p}$.

Wool T.M., Ambrose R.B. \& Martin J.L., 2001. Water Quality Analysis Simulation Program (WASP) Version 6 User's Manual. Atlanta: US Environmental Protection Agency. 